\title{
Do Risk Preferences Really Matter? The Case of Pesticide Use in Agriculture
}

\author{
Christophe Bontemps \\ Toulouse School of Economics, INRAE, University of Toulouse Capitole, Toulouse, France \\ Douadia Bougherara \\ CEE-M, Univ. Montpellier, CNRS, INRAE, Institut Agro, Montpellier, France \\ Céline Nauges \\ Toulouse School of Economics, INRAE, University of Toulouse Capitole, Toulouse, France
}

\begin{abstract}
Even if there exists an extensive literature on the modeling of farmers' behavior under risk, actual measurements of the quantitative impact of risk aversion on input use are rare. In this article we use simulated data to quantify the impact of risk aversion on the optimal quantity of input and farmers' welfare when production risk depends on how much of the input is used. The assumptions made on the technology and form of farmers' risk preferences were chosen such that they are fairly representative of crop farming conditions in the US and Western Europe. In our benchmark scenario featuring a traditional expected utility model we find that less than $4 \%$ of the optimal pesticide expenditure is driven by risk aversion and that risk induces a decrease in welfare that varies from $1.5 \%$ to $-3.0 \%$ for individuals with moderate to normal risk aversion. We find a stronger impact of risk aversion on quantities of input used when farmers' risk preferences are modeled under the cumulative prospect theory framework. When the reference point is set at the median or maximum profit, and for some levels of the parameters that describe behavior toward losses, the quantity of input used that is driven by risk preferences represents up to $19 \%$ of the pesticide expenditure.
\end{abstract}

Acknowledgements: Christophe Bontemps and Céline Nauges acknowledge funding from the French National Research Agency (ANR) under the Investments for the Future (Investissements d'Avenir) program, grant ANR17-EURE-0010. 


\section{Introduction}

In modern agriculture plant protection products are used to protect crops against harmful organisms. Their application on crop fields impacts both the expected crop yield and its variability (Just and Pope 1978; Feder 1979; Lichtenberg and Zilberman 1986). Farmers, who have been found to be risk averse in most situations, are using plant protection products not only to increase mean crop yields but also to manage the variance of yields induced by unpredictable shocks (Chavas 2019a). Even though a large number of empirical studies assessing the role of risk preferences on farmers' production decisions have been published, only rarely have authors actually reported by how much risk aversion impacts the use of plant protection products such as pesticides (Carpentier 1995; and Pannell 1995, are exceptions). Knowing by how much farmers' insurance motive drives their use of plant protection products matters for policy-making in a context of increased pressure on governments to regulate pesticides due to the negative externality they exert on human health and the environment. More precisely our findings should help policy makers thinking about the possible consequences of subsidizing insurance premiums or taxing pesticides. The purpose of this article is to provide additional insights into the (quantitative) impact of risk aversion on pesticide use and farmers' welfare.

The impact of risk aversion on input use remains an empirical question and the answer depends on the conditions under which farms operate, the direction and magnitude of the inputrelated risk (i.e., whether the input increases or decreases risk), and farmers' risk preferences. Since the main purpose of this work is to get a quite general answer to this question we use simulated data. We make initial assumptions about the form of the technology, the direction of the risk effect, the quantities of input used, and the form of farmers' risk preferences that are representative of crop farming in regions such as Western Europe and the United States (US). We then vary the parameters of the technology, the economic conditions (relative price of crop and pesticides) and the form of farmers' risk preferences in order to cover a wide range of realistic situations. 
Our (benchmark) situation is fairly simple: the representative farmer, who is risk averse, uses pesticides to produce some agricultural output (crop). Output is not known with certainty due to the presence of a random and unpredictable shock. In order to make the empirical analysis easy to follow and despite contrasting empirical evidence (e.g.; Pannell 1991; Möhring et al. 2020), we consider pesticides as a risk-decreasing input.' In the traditional Expected Utility (EU) framework, the optimal quantity of a risk-decreasing input used by a risk-averse farmer is above the risk-neutral optimum, since pesticides are used by risk-averse farmers to manage production risk. We compute the share of pesticide expenditure that is used by farmers for self-insurance by comparing the optimal level of input use under a risk neutrality assumption to the optimal level of input use under the assumption that the farmer is risk averse. We also report the change in farmer's welfare induced by risk aversion with respect to the risk-neutrality case. Along the lines of Pannell (2006) and Chavas (2019a) welfare is measured by the certainty equivalent, which is defined as the difference between the expected profit and the risk premium. If pesticides were assumed risk increasing instead, then risk-averse farmers would use less of the input to self-insure against production risk. We do not consider this case in the empirical analysis to follow. We argue this is not a major limitation of our work since the main outcome of interest, here the change in input use and welfare induced by risk aversion, would be comparable in magnitude (only the direction of the change, positive vs. negative, would differ).

Under fairly representative production conditions and for what is considered a normal or average level of risk aversion (relative risk aversion coefficient of 1 or 2 ), we show that less than $4 \%$ of the optimal input use is devoted to risk management. Welfare change induced by risk aversion is found to vary from $-1.5 \%$ to $-3.0 \%$ for relative risk aversion coefficients of 1 and 2 , respectively. These results are found to be robust to changes in the parameters of the production technology and economic conditions (relative prices of pesticides and crop). These findings are in line with those reported in Carpentier (1995) for French cereal producers and in Pannell (1995) using data from field experiments conducted in Australia. Our results also echo those of Pannell, Malcolm and Kingwell (2000) and Pannell (2006). As part of a general discussion on the (usual) flatness of the payoff 
functions in agriculture (i.e., the fact that optimal input use often lies on the plateau of the profit and certainty equivalent functions), they documented that taking risk aversion into account only changes the optimal farmer's strategy by moderate amounts and hence does not greatly affect farmers' welfare. These authors also reported that, even if the optimal input level does change, there is almost no effect on welfare. Indeed they argued that the input elasticity of welfare is close to zero for quite wide ranges of input levels.

In the second part of this article we allow for more flexible forms of risk preferences and behavioral attitudes by considering the Cumulative Prospect Theory (CPT) framework (Tversky and Kahneman 1992) instead of the more restrictive EU framework. Recent findings suggest that CPT offers a more accurate representation of farmers' risk preferences (see, e.g., Bocquého, Jacquet and Reynaud 2014; Babcock 2015; Bougherara et al. 2017; Chavas 2019b). The CPT framework allows for distortion in probabilities, the setting of a reference point that defines gains and losses with possibly different behaviors in response to gains and losses, and loss aversion. Our results show that, when the reference point is set at the median or maximum profit, and for some levels of the parameters that describe behavior toward losses, the quantity of input used that is driven by risk represents up to $19 \%$ of the pesticide expenditure under the baseline economic conditions. This figure is even higher for different assumptions about the pesticides-crop ratio. These findings thus call for additional research on farmers' preferences measured under the more flexible CPT framework.

Our general conclusion about the rather moderate role of pesticides for self-insurance purposes under the EU framework to some extent echoes findings from the empirical literature on crop insurance. Just, Calvin and Quiggin (1999) showed that participation in crop insurance is primarily seen by US farmers as a way to get some income support (through the subsidization of insurance by the government) rather than being a risk management tool. Our findings also seem to align with the empirical evidence that participation in crop insurance has a limited impact on US 
farmers' chemical input use (e.g., Smith and Goodwin 1996; Goodwin, Vandeveer and Deal 2004; Weber, Key and O’Donoghue 2016).

In the next section we review some related literature and we explain how our modeling choices build on earlier contributions. Then we describe the farmer's optimization program in the traditional EU framework and we derive the first order condition for optimal input use, which allows components related to profitability and self-insurance to be identified. We then describe the benchmark model, including the chosen production function and the farmer's model of preferences under risk. We comment on our findings under the benchmark situation and for various levels of risk aversion. We run some sensitivity analyses assuming different economic conditions (pesticides-crop price ratio) and different parameters of the technology. We also discuss the validity of our underlying assumptions and the direction of possible biases. Finally we consider utility models derived from the CPT framework and the last section concludes.

\section{Literature Review}

There exists an extensive empirical literature assessing the role of risk preferences on farmers' production decisions (see, e.g., Chavas 2019a, for a recent overview) but actually very little that provides a direct measurement of the quantity of input used that is induced by risk aversion (Carpentier 1995; Pannell 1995). Other relevant studies include those that have quantified the cost of risk on farmers' welfare through the calculation of a risk premium and certainty equivalent, and some empirical studies from the US on farmers' participation in crop insurance programs.

Carpentier (1995) is one of the rare studies that provide a direct measurement of the

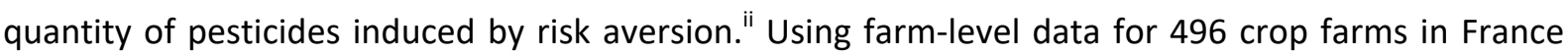
over the years 1987-1990, this author modeled farmers' decisions within an EU framework and assuming a Just-Pope production technology (Just and Pope 1978, 1979). The vast majority of farmers in the sample were found to be risk averse and their risk aversion induced an increase in input use that represented from $7 \%$ (for low risk-averse farmers) to $12 \%$ (for high risk-averse 
farmers) of their pesticide expenditure. In addition the risk premium for the most risk-averse farmers represented $7 \%$ of their pesticide expenditure and $2 \%$ of their gross margin. In Pannell (1995) herbicides are modeled as damage control inputs in the crop yield function (cf. Lichtenberg and Zilberman 1986, discussed later in this section). Various sources of risk are considered (e.g., weed density, weed-free yield, output price) and farmers' utility is assumed to be of the Constant Absolute Risk Aversion form. Using field experimental data and numerical methods, the author looked for optimal solutions for a typical Australian farm producing 1,200 hectares of wheat. Risk aversion was found to have limited influence on the optimal herbicide application, whatever the source of uncertainty. If all uncertainties are combined the difference in terms of optimal input application between a risk-neutral farmer and a rather risk-averse farmer is around $12 \%$.

Pannell, Malcolm and Kingwell (2000) and Pannell (2006), building on evidence from several empirical studies, documented that the cost of (wrongly) assuming farmers' risk neutrality (if farmers were indeed risk averse) induces a very small loss in farmers' welfare. For example, analyses made on data from Western Australia showed that the effect on welfare if a risk-averse farmer uses the quantity of input that is optimal under risk neutrality is very small (the certainty equivalent changes by less than $1 \%$ even under the assumption of a relatively high risk aversion). The authors argued that the small impact of risk aversion on welfare is due to the flatness of both the production and certainty equivalent functions and the fact that the region of the optimum often lies in the flat portion of the curve.

Regarding the impact of risk on welfare, Chavas (2019b) estimated the cost of risk in terms of corn production (in bushel/acre) for conventional and Genetically Modified (GM) seeds using experimental data from Wisconsin. The cost of risk here corresponds to the quantity of output the decision-maker is willing to forego to eliminate the risky payoff and replace it by its mean. Corn yield distribution is estimated by quantile regression and farmers' risk preferences are modeled within both EU and PT frameworks (under the assumption of a constant relative risk aversion coefficient 
equal to 2 in the EU model, hence representing moderate risk aversion). Depending on the type of crop rotation (corn after corn or corn after soybean) and assumption on risk preferences, the cost of risk represents 11 to $19 \%$ of mean yield with conventional seeds, and 1 to $8 \%$ with the GM seeds.iii

Di Falco and Chavas (2006), using farm-level data on durum wheat produced in Sicily (Italy), estimated that the risk premium varies between 6 and $12 \%$ of expected revenue, depending on crop genetic diversity. Their analysis relied on a moment-based approach (Antle 1983) that allows not only the mean and variance of yield, but also its skewness to be considered. The latter can be seen as an extension of the Just-Pope model that takes into account the third moment of the distribution. Farmers' preferences were assumed to be characterized by Decreasing Absolute Risk Aversion (DARA) preferences with a coefficient of relative risk aversion set at $2 .^{\text {iv }}$

Bontems and Thomas (2000), using data collected for rain-fed corn plots from the US Midwest on yield, nitrogen application and other practices at the plot level, estimated that the risk premium (related to production risk) was $8 \%$ of profit per acre. In their structural model the yield function was specified as a Translog functional form while preferences were described using a Constant Relative Risk Aversion utility function (which implies DARA preferences).

Finally a set of empirical studies undertaken for the most part in the US assessed the impact of crop insurance on chemical input use. In most cases results show that the purchase of crop insurance induced a decrease in chemical input usage but the magnitude of the impact is generally found to be small. Among other examples, Quiggin, Karagiannis, and Stanton (1993) found that Midwestern farmers who purchased crop insurance reduced fertilizer and chemical application by about 10\%. Goodwin, Vandeveer and Deal (2004) found similar negative effects of insurance adoption on the expenditure on chemical inputs for wheat and barley producers from the Northern Great Plains. Impacts of similar magnitude were obtained by Smith and Goodwin (1996) for Kansas wheat producers and by Goodwin and Smith (2003) on county-level data for the US as a whole. In Wu (1999), crop insurance participation (for farmers in Nebraska) was found to increase chemical input 
use due to the extensive margin effect (crop insurance induced a shift from hay and pasture to corn and hence an increase in chemical input usage) being greater than the intensive margin effect (a reduction in chemical input use on a per hectare basis). Using farm-level data from the US over the years 2000-2013, Weber, Key and O'Donoghue (2016) estimated that doubling crop insurance premiums would lead to a $1.9 \%$ increase in pesticide expenses (upper-bound estimate). The above findings that crop insurance has little impact on chemical input use echo the analysis of Just, Calvin and Quiggin (1999). Using nationwide farm-level data these authors disentangled the incentives of crop farmers to participate in an insurance scheme into a risk management incentive, a subsidy incentive (through government subsidization of insurance) and an asymmetric information motive (induced by personal information known to the farmer only). They found that the primary incentive for participation in a crop insurance scheme is to get some income support (subsidy incentive) while the risk aversion incentive is rather small.

The majority of the above-cited studies rely on structural approaches modeling both risk preferences and the technology (production function). In most cases a Just-Pope production function is embedded in an EU model that describes the decision-making process of risk-averse farmers. This framework has been used widely for the analysis of production decisions under risk (e.g. Love and Buccola 1991; Saha, Shumway and Talpaz 1994; Chavas and Holt 1996; Koundouri et al. 2009). This is also the approach we propose to follow in this article. ${ }^{v}$

Just and Pope $(1978,1979)$ 's proposed specification for the production function is made up of two terms: the mean output function, which represents the impact of input on mean yield; and the risk function, which allows inputs to impact the variance of yield. This particular form of the production technology directly echoes Feder (1979)'s description of farmers' two main motives for using pesticides: increase of mean yield and self-insurance. Lichtenberg and Zilberman (1986) developed a (concurrent) production model where pesticides were specified as damage control inputs and not as productive inputs. They argued that their specification should lead to more 
accurate estimates of pesticides marginal productivity than production functions which do not distinguish between productive and damage control inputs. Using farm data from France, Carpentier and Weaver (1997) showed that the estimates of the marginal productivity of pesticides are not sensitive to the choice of the functional form but that the treatment of heterogeneity bias matters. In their review of the literature, Skevas, Oude Lansink and Stefanou (2013) reported that the specification of the production function may have non-negligible impacts on the estimated marginal productivity of pesticides in some cases but they concluded that there is no clear-cut evidence about which one should be preferred. Since there is no conclusive evidence about the superiority of one production model versus the other, and because we are primarily interested in assessing the role of risk preferences on input use, we specify the technology as a Just-Pope function in the empirical application to follow.

\section{The Farmer's Optimization Program}

In the benchmark scenario we assume farmers' decision-making under risk can be adequately described within the traditional EU framework. Along the lines of earlier literature we assume that farmers choose the quantity of input that maximizes the expected utility of their profit (e.g., Love and Buccola 1991; Chavas and Holt 1996; Koundouri et al. 2009). We consider a Just-Pope production technology featuring a single output (a crop) and a single input (here pesticides). ${ }^{\text {vi }}$ We also assume farmers face production risk only (i.e., prices are known with certainty). In the later sections the parameters of the production technology will be varied and we will adopt a more flexible representation of farmers' preferences under risk.

We consider a farmer producing a single crop $(y)$ from a single input $(x$, which represents pesticides). The output price $(p)$ and the price of the input $(r)$ are assumed to be known by the farmer. We specify the relationship between input and output as a Just-Pope production technology in which input $x$ impacts both the mean yield and the variance of yield. The production function also allows for the possibility of a random shock of mean $0, \varepsilon$, over which the farmer has no control. In 
most situations when the agricultural output is a crop, the random shock represents random weather conditions and pest infestations. The production technology is specified as follows:

$y=f(x)+g(x) \varepsilon$

with $\partial f / \partial x>0$ and $\partial g / \partial x<0$. The first condition indicates that applying greater quantities of pesticides $x$ increases crop yield, with $\partial f / \partial x$ measuring the marginal productivity of pesticides. The second condition represents the risk-reducing property of pesticides in the sense that larger quantities of pesticides contribute to a reduction in the variance of crop yield. This assumption is not always true and is made mainly for convenience.

The farmer is assumed to choose the optimal level of input $x$ such that it maximizes their utility. If the farmer is risk neutral, their utility is measured by the expected profit and the maximization program reads as follows:

$\max _{x} E(\pi)=E(p y-r x)=E[p(f(x)+g(x) \varepsilon)-r x]=p f(x)-r x$.

We denote by $x_{0}^{*}$ the optimal level of input $x$ if the farmer is risk neutral, which is the solution of the following first order condition:

$\frac{\partial f}{\partial x}=\frac{r}{p}$ or equivalently $p \frac{\partial f}{\partial x}=r$.

If the farmer is risk neutral then the optimal level of input use is such that the revenue (in monetary terms) generated by the use of one additional unit of pesticides ( $\left.p \frac{\partial f}{\partial x}\right)$ is equal to the cost of this additional unit $(r)$. If the farmer is risk averse and if we assume that the EU model adequately represents their preferences, the farmer will instead maximize the expected utility of profit: 
$\max _{x} E U(\pi)=E[U(p y-r x)]=E[U(p[f(x)+g(x) \varepsilon]-r x)]$

where $U($.$) is a concave utility function assumed to be continuous and differentiable, and the$ optimal level of input $x^{*}$ is the solution of the following first order condition:

$$
\underbrace{\frac{\partial f}{\partial x}}_{(A)}=\underbrace{\frac{r}{p}}_{(B)}-\underbrace{\frac{\partial g}{\partial x}}_{(C)} \underbrace{\frac{E\left[U^{\prime}(\pi) \varepsilon\right]}{E\left[U^{\prime}(\pi)\right]}}_{(D)} .
$$

Condition (5) is made up of four components: (A) the marginal productivity of pesticides (in physical terms); (B) the pesticides-crop price ratio; (C) the risk-reducing effect of pesticides; and (D) a measure of farmer's risk preferences. Components (A) and (B) both determine the expected profitability of pesticides while the (C) and (D) components capture the impact of risk. If the farmer is risk neutral then (D) is equal to 0 and condition (5) reduces to condition (3). If the farmer is risk averse, then (D) is strictly greater than 0 and $x^{*}>x_{0}^{*}$. The optimal input use under risk aversion is greater than the optimal input use under risk neutrality. Since we assume pesticides are a riskdecreasing input, a risk-averse farmer will use more pesticides than a risk-neutral farmer at the optimum. In what follows we compare the optimal use of pesticides under a risk neutrality assumption (i.e. when $D=0$ ) and the optimal use of pesticides under the assumption that the farmer is risk averse, (i.e. when $D>0$ ) under fairly representative assumptions about the technology and risk preferences. We also document the change in welfare induced by risk aversion.

\section{Description of the Benchmark Case}

We describe in turn the production technology and the utility function that have been chosen for the benchmark scenario.

\section{Production Technology}

We consider the following Just-Pope production function: 
$y=f(x)+g(x) \varepsilon=a x^{\alpha}+b x^{\beta} \varepsilon$,

with $a, b>0, \alpha>0, \beta<0$, and $\varepsilon$, a random shock assumed to be of mean 0 . The parameters of the production function were chosen such that the function fits real production data; that is: $y=15 x^{0.3}+30 x^{-0.10} \varepsilon{ }^{\text {vii }}$ The elasticity of mean output (0.3) and the elasticity of output variance ($0.10)$ to input use are in the range of those reported in the literature (see Appendix A1).

For simplicity and without any loss of generality we assume the farmer owns one unit of land (equivalent to one hectare). In Equation (6) and from now on $x$ represents pesticide expenditure (i.e., we assume the price of input $r$ is normalized to 1 ). In line with observational data for cereal farmers from France, we consider possible values for $x$ varying from 1 to 400 EUR for one hectare. Output $y$ is wheat and is measured in quintal $(1 \mathrm{q}=0.1 \mathrm{t}=100 \mathrm{~kg})$. We set the price of wheat $(p)$ at $110 \mathrm{EUR} / \mathrm{t}$ or, equivalently, $11 \mathrm{EUR} / \mathrm{q}$, which corresponds to the observed median price on the sample of French crop farms. Figure 1 illustrates the production technology for input quantities varying from 1 to 400 EUR and for the random shock $\varepsilon$ being set at 0 .

[Figure 1 around here]

To account for uncertainty in the empirical analysis to follow we assume that the random shock $\varepsilon$ follows a standardized normal distribution. We randomly draw 1,000 $\varepsilon_{i} \quad(i=1,2 \ldots 1,000)$ from a $N(0,1)$ distribution and we calculate crop yield and corresponding profit for each input level (varying from 1 to 400) and for each of the 1,000 random shock values. ${ }^{\text {viii }}$ The calculated profit varies in the range $[-1,000$ EUR; 1,500 EUR].

\section{Utility Function}

In the benchmark scenario we assume farmers' decision-making under risk can be adequately described using the traditional EU framework. In line with most empirical evidence, we assume farmers are risk averse (Chavas 2004, 2019a). One of the most commonly used utility functions in the 
agricultural economics literature features a constant relative risk aversion (CRRA) coefficient typically in the range of 0 (corresponding to risk neutrality) to 4 (corresponding to a high level of risk aversion); see Chavas (2004) and Gollier (2004). ${ }^{\text {ix }}$ In what follows we adopt Anderson and Dillon (1992)'s terminology: a coefficient of 1 for somewhat risk averse; 2 for rather risk averse; 3 for very risk averse; and 4 for extremely risk averse. Coefficients of 1 and 2 are considered as "normal" and have been used to characterize farmers' risk aversion in recent studies (e.g., Di Falco and Chavas 2006; Chavas 2019b). CRRA utility functions imply Decreasing Absolute Risk Aversion (DARA) and aversion to downside risk, some characteristics which are commonly observed in farmers' populations (Chavas 2004).

The utility function has the following form:

- the logarithmic function when $r_{r}=1: U(w)=\ln (w)$ with $w$ representing wealth $(w>0)$ and $r_{r}$ the coefficient of relative risk aversion;

- the power function when $r_{r}$ is different from 1: $U(w)=\left\{1 /\left(1-r_{r}\right)\right\} w^{1-r_{r}}$ with $w>0$

Since the utility function is defined only for wealth being strictly positive, we define $w$ as the sum of the profit earned from agricultural activity ( $\pi$, which may be negative under bad shocks) and some initial wealth $w_{0}$ which is constant and not affected by the random shock (see, e.g., Sckokai and Moro 2006, for similar assumptions). We define $x_{0}^{*}$ and $x^{*}$ as the quantity of input that maximizes the expected profit (risk-neutrality case) and the expected utility of profit (risk-averse farmer), respectively.

The cost of risk is measured by the risk premium (RP), which is the amount of money the farmer would be willing to forego to avoid facing risk and is defined by the following relationship:

$E[U(w)]=U[E(w)-R P]$. 
The term $E(w)-R P$ corresponds to the Certainty Equivalent (CE), which can be seen as a measure of farmers' welfare when farmers are risk averse (Chavas 2004). Later we will consider the more sophisticated CPT framework to allow for more flexibility in farmer's description of preferences under risk.

\section{Simulation Results: Expected Utility Framework}

Throughout the empirical exercise we set the initial wealth $w_{0}$ at 500 EUR. Since the utility function is of the CRRA-type (which implies Decreasing Absolute Risk Aversion or DARA), production decisions including the optimal input use depend on initial wealth (Hennessy 1998). Increasing the level of initial wealth will reduce the private cost of risk bearing and hence the impact of risk aversion on pesticide use. We set initial wealth at 500 EUR, which is of the same order of magnitude as the mean profit and such that wealth ( $w$, defined as the sum of the initial wealth and profit in the utility model) is positive under almost all possible cases (i.e., even under the most unfavorable random shocks). By choosing a rather small level of initial wealth we minimize the risk of under-estimating the impact of risk aversion on pesticide use.

\section{Benchmark Scenario}

In Table 1 we report the optimal level of input use, the risk premium, and the certainty equivalent (all measured in EUR for one hectare) under the risk neutrality assumption $\left(r_{r}=0\right)$ and under risk aversion for four different levels of the coefficient of relative risk aversion $\left(r_{r}=1,2,3\right.$ and 4). ${ }^{x}$ The quantity of input that is used for self-insurance purposes is computed, for each level of risk aversion, as the difference (in percentage terms) between the optimal input use under risk aversion $\left(x^{*}\right)$ and the optimal input use under risk neutrality $\left(x_{0}^{*}=264\right)$. We also report the change in welfare or certainty equivalent when moving from a risk-neutral situation to a risk-averse situation, for each level of risk aversion. 
[Table 1 around here]

Under fairly common assumptions about the technology and economic conditions a riskneutral farmer spends 264 EUR for pesticides while pesticide expenditure for a risk-averse farmer varies from 268 to 285 EUR for the most extreme risk aversion level $\left(r_{r}=4\right)$. For coefficients of relative risk aversion considered as normal or average $\left(r_{r}=1\right)$, a risk-averse farmer spends an extra 4 EUR compared to a risk-neutral farmer to self-insure, which corresponds to $1.5 \%$ of total expenditure on pesticides. For a rather risk-averse farmer $\left(r_{r}=2\right), 3.3 \%$ of the total expenditure on pesticides is used for risk management purposes. In the more extreme case of $r_{r}=4,7.4 \%$ of the total expenditure in pesticides is used for self-insurance purposes.

The risk premium (RP) is the amount of money the farmer would be willing to forego to avoid facing risk. It is estimated at 17 EUR for an average risk-aversion level $\left(r_{r}=1\right)$. This corresponds to a 1.5\% decrease in welfare compared to the risk-neutral case. For a rather risk-averse farmer $\left(r_{r}=2\right)$, the risk premium is 34 EUR and this represents $3 \%$ of the certainty equivalent (CE) or welfare. For a more extreme level of risk aversion $\left(r_{r}=4\right)$, the cost of risk corresponds to $6.3 \%$ of welfare. Following Pannell (2006) we also computed the impact on welfare (or CE) if a risk-averse farmer uses the level of pesticides that is optimal under risk neutrality (264 EUR). Whatever the level of risk aversion the impact on welfare is found to be less than $1 \%$.

\section{Sensitivity Analysis}

The optimal level of input use under risk aversion $\left(x^{*}\right)$ is the solution to the first order condition (5) reproduced here:

$$
\underbrace{\frac{\partial f}{\partial x}}_{(A)}=\underbrace{\frac{r}{p}}_{(B)}-\underbrace{\frac{\partial g}{\partial x}}_{(C)} \underbrace{\frac{E\left[U^{\prime}(\pi) \varepsilon\right]}{E\left[U^{\prime}(\pi)\right]}}_{(D)} .
$$


In addition to the strength of risk aversion (D), the optimal input use depends on the pesticides-crop ratio (B), the parameters $a$ and $\alpha$ (see equation (6)) of the mean function ( $A$ term), and the parameters $b$ and $\beta$ (see equation (6)) of the risk function ( $C$ term). We first discuss the sensitivity of our outcome variables $\left(x^{*}\right.$ and $\left.\mathrm{RP}^{*}\right)$ to the pesticides-crop price ratio and then to the parameters of the technology (production function).

\section{Sensitivity to the Pesticides-Crop Price Ratio}

Crop prices have varied significantly over the last ten years. Wheat prices reached a peak in 20072008 where the price was close to $300 \mathrm{EUR} / \mathrm{t}$. The price went down to around $130 \mathrm{EUR} / \mathrm{t}$ in 20092010. Over the last five years we have observed price fluctuations around $180 \mathrm{EUR} / \mathrm{t} .{ }^{\mathrm{xi}}$ We expect higher crop prices to provide an incentive for farmers to increase yields by using greater quantities of pesticides.

In the benchmark the ratio of the price of pesticides to the crop price was 1 to 11 . We test how our results change when considering the following cases: one case of a higher crop price (ratio of 1 to 13 , which corresponds to an $18 \%$ increase in output price) and two cases of a lower crop price (ratio of 1 to 9 and 1 to 7 , a decrease by $18 \%$ and 36\% respectively of the output price compared to the benchmark scenario). Results on optimal input use (in EUR), the share of pesticide expenditure used for self-insurance purposes (\%), the risk premium (in EUR) at the optimum and its share in total welfare (\%) are shown in Table 2.

[Table 2 around here]

The price ratio has a large impact on the level of optimal input use. A risk-neutral farmer spends 264 EUR for one hectare when the pesticides-crop price ratio is 1 to 11 (benchmark situation), but 335 EUR ( $27 \%$ increase compared to the benchmark) when the price ratio is 1 to 13 , and 138 EUR ( $48 \%$ decrease) when the price ratio is 1 to 7 . If the quantity of pesticides used changes significantly with prices for any given level of risk aversion, the share of pesticide expenditure that is 
used for insurance purposes varies moderately across levels of risk aversion for a given price ratio. The share of pesticide expenditure that is used for risk management purposes varies from $1.5 \%$ to $2.1 \%$ in the case of a moderately risk-averse farmer $\left(r_{r}=1\right)$. The most extreme case is when the farmer is highly risk averse $\left(r_{r}=4\right)$ and crop price is low (ratio of 1 to 7$)$. In this case $8.6 \%$ of total pesticide expenditure is used for insurance motives.

In the benchmark situation the risk premium was estimated at 17 EUR for a moderately riskaverse farmer $\left(r_{r}=1\right)$ and this risk premium represented $1.5 \%$ of the certainty equivalent. For the same level of risk aversion, the risk premium varies from 10 EUR when the crop price is low (ratio of 1 to 7 ) to 19 EUR when the crop price is high (ratio of 1 to 13 ). The share of the risk premium in total welfare is less than $2 \%$ whatever the price ratio.

These simulations show that, under fairly representative conditions on the production technology and risk preferences, the quantity of input used is much more sensitive to price changes (B component in equation (5)) than to the strength of risk aversion. Also, for a given level of risk aversion the relative cost of risk (i.e., the risk premium as a share of the certainty equivalent) remains almost unchanged whatever the price ratio.

\section{Sensitivity to the Technology Parameters}

We first vary the parameters $a$ and $\alpha$ of the mean yield function $f(x)$ and test the sensitivity in terms of optimal input use, RP and CE (Table 3). We consider three values for the exponent $\alpha$ of the mean function $(0.20,0.25$ and 0.30 , the last of these corresponding to the benchmark case). Graphs illustrating profit functions and optimal input use under various assumptions on the parameters of the mean function are shown in Appendix A3. With $\alpha$ greater than 0.30 , the optimal input use is greater than 400, which we consider not to be realistic. We then vary the parameters $b$ and $\beta$ of the risk function $g(x)$. The optimal level of input use is found not to be very sensitive to the parameters of the $g($.$) function so results are shown in Appendix A4.$ 
[Table 3 around here]

Unsurprisingly the optimal quantity of input use is very sensitive to the parameters of the mean yield function. As expected the optimal use of pesticides is higher when the marginal productivity of pesticides increases. For example, the optimal expenditure under a risk neutrality assumption increases from 264 EUR to 342 EUR for one hectare when the multiplicative coefficient (a) of the mean yield function increases from 15 (benchmark) to 18. When the multiplicative coefficient (a) is 10 , the optimal input use under a risk neutrality assumption is 148 EUR. The optimal quantity of input use is also highly sensitive to the elasticity of output to pesticides ( $\alpha$ in the mean function). In the benchmark (elasticity set at 0.3 ), the optimal input expenditure under a risk neutrality assumption is 264 EUR while it is 79 EUR when the elasticity is set at 0.2 .

As expected also, when the marginal productivity of pesticides is higher (either because of a larger multiplicative coefficient $a$ or a higher elasticity $\alpha$ ) then the share of pesticide expenditure that is used for self-insurance purposes decreases. In the benchmark case $\left(y=15 x^{0.3}+30 x^{-0.10} \varepsilon\right)$ and for a normal level of risk aversion $\left(r_{r}=1\right), 1.5 \%$ of pesticide expenditure is driven by risk aversion and the risk premium represents $1.5 \%$ of welfare. If the elasticity of output to pesticide use $(\alpha)$ is set at 0.2 instead of 0.3 then $9.2 \%$ of the expenditure on pesticides is used to compensate for risk and the risk premium increases to $3.7 \%$ of welfare. Similarly if the multiplicative coefficient in the mean function $(a)$ is set at 18 instead of 15 then the impact of risk is smaller: $1.2 \%$ of total pesticide expenditure is used for self-insurance and the risk premium represents $1 \%$ of welfare.

Results for various parameters of the risk function are shown in Appendix A4. The share of pesticide expenditure that is used for self-insurance purposes varies with the multiplicative coefficient $(b)$ and the exponent of the risk function $(\beta)$. An increase in $b$ and an increase in the (negative) exponent $\beta$ both increase the importance of the risk component (relative to the mean component) in the production function. Consequently the share of pesticide expenditure that is used for risk purposes is higher, all other things equal, when $b$ is set at 40 instead of 30 , and when $\beta$ is set 
at -0.1 instead of -0.2 . For a rather normal level of risk aversion $\left(r_{r}=1\right)$ the share of pesticide expenditure that is driven by risk varies between $0.8 \%$ and $3.3 \%$. In the most extreme case $(b=40$ and coefficient of relative risk aversion $\left.r_{r}=4\right), 14.6 \%$ of pesticide expenditure is driven by risk aversion.

Coming back to equation (5) and the four components that define the first order condition on optimal input use, we find that any change (in relation to the parameters of the technology or the economic conditions) that increases the weight of the "profitability components" (A) and (B) induces an increase in pesticide use, for any given level of risk aversion. If the expected profitability (or mean yield) increases then farmers have an incentive to apply more pesticides, whatever their level of risk aversion. Still, the share of pesticides used for self-insurance purposes is almost unchanged.

\section{Robustness to the Assumptions on Technology and Risk Preferences}

Our framework covers a wide range of situations but builds on a set of assumptions: we consider a Just-Pope production technology with a single risk-decreasing input (pesticides) and we assume farmers face production risk only. We argue that these assumptions most likely produce an overestimate of the use of pesticides as a risk management tool. If other inputs were considered, such as labor or fertilizers, they may also be used to manage risk and hence may attenuate the role of pesticides as a risk management tool. If price risk was considered we also believe it is likely to lead to a decrease in the use of pesticides induced by risk aversion. This is because price risk and production risk are often negatively correlated which implies that adverse production shocks are partially compensated by positive price adjustments, hence leading to a change in expected revenue that is lower than under production risk only (Chavas 2019a).

As discussed earlier the assumption of pesticides being risk decreasing applies only to some situations and there exists empirical evidence of pesticides being risk increasing or having no effect on risk (Möhring et al. 2020). As said earlier we believe this assumption is not a major caveat of our study since the magnitude of the impact of risk aversion on input use is expected to be similar (but of 
the opposite direction) if pesticides were risk increasing instead. Moreover in our framework, pesticide use is measured with pesticide expenditure, which is a simplification. When available, information on both quantity and quality of pesticides should be considered since the risk properties of pesticides depend not only on the quantity used but also on their toxicity (Möhring, Gaba and Finger 2019; Möhring et al. 2020).

When describing farmers' preferences with a CRRA utility function we implicitly consider that farmers are averse to downside risk, which is line with empirical evidence (Chavas and Nauges 2020). However the third moment is not explicitly considered in the Just-Pope production function which models the mean and variance of yield only. ${ }^{\text {xii }}$ We argue that omitting the third moment is not a major limitation of our work. This is mainly for the reason that we are considering crop farming and describe situations which are representative of conditions in Western Europe and the US where the probability of crop failure is rather small and the distribution of crop yields is not highly skewed to the left. Our findings may not be transferable to places (such as Australia for example) where more extreme weather events such as large-scale flooding or prolonged droughts may occur with higher frequency. In the next section we consider the more flexible Cumulative Prospect Theory (CPT) framework.

One of the caveats of the CRRA functional form is that optimal input decisions of risk-averse farmers vary with wealth. We chose a rather low level of farmer's initial wealth (500 EUR) in order to minimize the wealth effect, but setting an initial wealth was necessary for the argument of the CRRA utility function (total wealth defined as initial wealth plus profit) to be greater than 0 . With an initial wealth set at 500 EUR and a risk aversion coefficient set at 4, the optimal input use is 285 EUR which corresponds to $7.4 \%$ of pesticide expenditure being used for risk management purposes (Table 1). If the initial wealth is increased to 1,000 EUR, the optimal level of input use for an extremely riskaverse farmer (risk aversion coefficient of 4) decreases to 277 EUR, which means $4.7 \%$ of pesticide expenditure are driven by risk. If initial wealth is set at 5,000 EUR then the optimal input use for an 
extremely risk averse farmer is 267 EUR, which is very close to the risk-neutral optimal level (264 EUR). Some more results are shown in Appendix A5.

\section{Results under the Cumulative Prospect Theory}

Recent studies have shown that CPT may be a more relevant alternative to the EU model to describe farmers' preferences under risk (Bocquého, Jacquet and Reynaud 2014; Babcock 2015; Bougherara et al. 2017). This theory permits a more flexible representation of individuals' choices by allowing for the following phenomena:

(i) Probability distortion: an inverse-S-shaped probability weighting function which converts probabilities into decision weights is used to account for low probability events commonly being over-weighted and high probability events usually being under-weighted. The intuition behind an inverse-S-shaped transformation function is that agents are pessimistic and place greater weight on the less likely events for which they are less experienced and consequently more anxious;

(ii) Reference dependence: individuals care about deviations from a reference point rather than the absolute initial or final wealth; values above the reference point represent gains and values below the reference point represent losses;

(iii) Reflection effect: a two-part utility function allows for differences in behavior in the two outcome domains (gains versus losses). The utility function is usually S-shaped: the curvature in the gain domain is reflected in the loss domain; concavity for gains (risk aversion) implying convexity for losses (risk seeking);

(iv) Loss aversion: "losses loom larger than gains" (Tversky and Kahneman 1992, p. 298). Losses are weighted, meaning that the disutility of a loss is stronger than the utility of a similar gain. 
We consider the value function described in Tversky and Kahneman (1992), which was also used in Babcock (2015) who studied crop insurance adoption using simulated data calibrated to an average crop farm in the US Midwest:

$v^{K T}(w)=\left\{\begin{array}{l}\left(\frac{1}{1-r r^{+}}\right)\left(w-w_{r e f}\right)^{\left(1-r r^{+}\right)} \text {if } w \geq w_{r e f} \\ -\left(\frac{1}{1-r r^{-}}\right) \lambda\left[\left(-w+w_{r e f}\right)^{\left(1-r r^{-}\right)}\right] \text {if } w<w_{r e f}\end{array}\right.$

Where $w$ is wealth, $w_{\text {ref }}$ is the reference point; $\lambda$ is a parameter measuring the degree of loss aversion; and $\mathrm{rr}^{+}$and $\mathrm{rr}^{-}$measure the curvature of the value function in the gain and loss domains, respectively. We consider only cases where $r r^{+}<1$ (risk aversion in gains) and $r r^{-}<1$ (risk seeking in losses) as in Babcock (2015). We have $\lambda \geq 1$ with $\lambda=1$ indicating no aversion to loss. ${ }^{\text {xiii }}$ When $\lambda>1$, the value function has a kink at the threshold or reference point $w_{\text {ref }}$. Loss aversion translates into cases where avoidance of a loss generates more value than the corresponding gain.

Under CPT individuals are assumed to maximize a weighted average value of all possible gains and losses with decision weights used instead of probabilities. Different probability weighting functions have been proposed in the literature. We follow Tversky and Kahneman (1992) and choose: $\Gamma(p)=\left\{\begin{array}{l}\frac{p^{\gamma}}{\left[p^{\gamma}+(1-p)^{\gamma}\right]^{1 / \gamma}} \text { if } w \geq w_{\text {ref }} \\ \frac{p^{\delta}}{\left[p^{\delta}+(1-p)^{\delta}\right]^{1 / \delta}} \text { if } w<w_{\text {ref }}\end{array}\right.$.

When $\gamma=\delta=1$, decision weights are equal to probabilities. When $\gamma$ and/or $\delta$ are different from 1, this accounts for the possibility of individuals giving less weight to high probability events and/or to 
overweight low probability events. When $\gamma=\delta=\lambda=1$ and $r r^{+}=r r^{-}=r_{r}$, the CPT model reduces to the EU model with constant relative risk aversion $r_{r}$. When these conditions are not satisfied and the preference function is not linear in the probabilities, we can no longer talk about "expected utility" for the CPT model and the parameters $\mathrm{rr}^{+}$and $\mathrm{rr}^{-}$can no longer be considered as a measure of risk attitudes. Since in CPT risk attitude also depends on other factors such as probability weighting, the parameters $r r^{+}$and $r r^{-}$in $v^{K T}$ are not directly comparable with the parameter $r_{r}$ in the CRRA utility model.

An individual who is risk averse in gains $\left(r r^{+}<1\right)$ will seek to insure while the overweighting of small probabilities of large gains $(\gamma<1)$ will decrease insurance demand. On the other hand, while an individual who is risk seeking in losses $\left(r r^{-}<1\right)$ will not insure, loss aversion $(\lambda>1)$ and the overweighting of small probabilities of large losses $(\delta<1)$ will induce the individual to insure. In the context of our study we expect farmers to increase the use of pesticides if they exhibit higher risk aversion in the gain domain (i.e., a low $r r^{+}$), higher probability distortion in losses (i.e., a low $\delta$ ), and higher aversion to losses (i.e., a high $\lambda$ ).

In what follows we consider as a baseline (CPT Scenario 0) the parameters reported in Tversky and Kahneman (1992) and also used in Babcock (2015) as a reference scenario and we then vary some of the parameters (for an overview of CPT parameter estimates among farmers' populations, see Appendix A6). We consider three possible threshold points: zero, the median profit, and the maximum profit. We follow Köszegi and Rabin (2007) who advocate the use of the expected outcome as the main reference point but we also consider maximum profit which can be seen as the best outcome the farmer can hope for. ${ }^{\text {xiv }}$ The optimal input use and the share of pesticide expenditure driven by risk are shown in Table 4 for various CPT scenarios.

[Table 4 around here] 
In the baseline case (Scenario 0 ) the optimal use of pesticides increases by $2.9 \%$ compared to the risk-neutral case (264 EUR) if the reference point is set at 0 . Stronger probability distortion in losses (Scenario 1) has no additional impact on pesticide use $(+2.9 \%)$ while stronger risk aversion in gains (Scenario 2) leads to a slight increase in the use of pesticides (6.0\%) compared to the riskneutral situation. Under the assumption of a threshold set at 0 we observe no additional increase of pesticides use for any combination of parameters in Scenarios 3 and 4 as compared to Scenario 2.

In the baseline the optimal use of pesticides increases by around $4 \%$ if the reference point is set at the median profit or at the maximum profit (note that median and maximum profit are very close). A non-zero reference point means that a higher range of profits is considered as losses by the farmer. As a consequence we expect parameters that describe preferences with respect to losses to have a stronger effect on pesticide use when the reference point is set at the median and maximum profits, and this is what we observe. A stronger probability distortion in losses (Scenario 1) has a slight additional impact on pesticide use (4\%) while stronger risk aversion in gains (Scenario 2) increases pesticide use by about $9 \%$ compared to the risk neutral situation. When comparing Scenarios 1 and 2 to the baseline scenario, increases in pesticide use follow similar patterns whatever the level of the reference point (zero, median or maximum). The largest increases in pesticides used are observed for Scenarios 3 and 4, for non-zero reference points, and when we consider both a stronger risk aversion in gains and a higher distortion in the probability of losses. Under these scenarios 17 to $19 \%$ of pesticide use is driven by risk (since we assume an upper bound of 400 EUR for the quantity of pesticides used, the maximum increase in pesticides that our model can produce for a 1 to 13 price ratio is $16 \%$ ). Increasing loss aversion to 3.50 instead of 2.25 in Scenario 4 only leads to very minor changes in the quantity of pesticides used. ${ }^{\mathrm{xv}}$ The risk premium varies from 20 to 85 EUR depending on the scenarios, hence in the same range of what was observed with EU-type preferences. 
To summarize, under CPT and for a reference point set as 0 , we find that quantities of pesticide used for self-insurance purposes are moderate and in the range of those obtained under the EU framework. However, the share of pesticides used that is induced by risk increases up to 17$19 \%$ when considering non-zero reference points and for some combinations of the risk preference parameters. Finally we explore the sensitivity of our results to the pesticides-crop price ratio using the median profit as the reference point (Table 5). Scenarios 3 and 4 lead to the highest increase in pesticide use with a $21-23 \%$ increase for a 1 to 7 price ratio.

[Table 5 around here]

\section{Conclusion}

Under fairly common assumptions (Just-Pope production technology, CRRA utility function, and economic conditions in line with observational data), our simulations in the benchmark scenario show that risk aversion induces an increase in the use of pesticides which is in the range of 2 to $3 \%$ for moderate levels of risk aversion ( $r_{r}=1$ or 2 ) compared to a risk-neutral scenario. In the case of a rather extreme risk aversion $\left(r_{r}=4\right)$ the amount of pesticides which is applied for risk management purposes represents $7.4 \%$ of pesticide expenditure. The risk premium varies from 17 to 71 EUR for one hectare and represents between 1.5 and $6.3 \%$ of the certainty equivalent. Sensitivity analyses under the EU framework show that the level of optimal input use, for a given level of risk aversion, is highly sensitive to both the parameters of the function that describes the technology and the pesticides-crop price ratio. The impact on pesticide use is large but, for a given price ratio or for given parameters of the production technology, the quantity of pesticides used that is driven by risk remains not very sensitive to the level of risk aversion.

All in all our quantitative results on extra input use driven by risk aversion and welfare impact of considering risk aversion under the EU framework are in the range of those reported by Carpentier (1995) for French crop farmers and by Pannell $(1995,2006)$. They provide yet another example of optimal input use and welfare being marginally affected by risk aversion due to optimality points 
lying in the flat portion of the profit and certainty equivalent functions. The cost of risk that we estimate (as measured by the risk premium) is also similar in magnitude (relative to the expected profit or certainty equivalent) to figures reported in Bontems and Thomas (2000) and Di Falco and Chavas $(2006,2009)$. The rather limited impact of risk aversion (in most situations) may provide some explanation for the findings of Just, Calvin and Quiggin (1999) that participation in crop insurance schemes is not primarily driven by risk aversion and that crop insurance adoption has a small impact on chemical input use (e.g., Goodwin, Vandeveer and Deal 2004; Smith and Goodwin 1996). Our findings are based on simulated data so we encourage researchers, when possible, to go beyond the measurement of risk preferences and to try and quantify the impact of risk aversion on input use (or any other farmers' decisions) in order to obtain further evidence on the (quantitative) impact of risk, either from observational or experimental data.

The results obtained under the CPT framework indicate possible larger impacts of risk preferences on optimal input use. In particular in situations where the reference point is set at the median or maximum profit, where the farmer is less risk-seeking in losses than risk-averse in gains, and where they highly distort probability of losses, the quantity of input used that is driven by risk increases up to $19 \%$ of pesticides used (this percentage is even higher under pesticides-crop price ratios different from the one used in the baseline scenario). Contrary to the EU framework for which we have a large number of empirical estimates of risk aversion parameters and a relatively precise idea of its range, there are only a few measures of risk preference parameters estimated under a CPT framework, especially for farmers' populations from the US and Western Europe. This dearth of empirical evidence makes it difficult to judge whether the preference parameters used in our simulations (Tables 4 and 5) are realistic or not. These findings thus call for more research on farmers' risk preferences using underlying models that go beyond the EU framework and that allow for loss aversion and distortion in probabilities. Our findings also illustrate the sensitivity of results to the choice of the reference point, something for which there exists very limited theoretical guidance (Barberis 2013). 
Our analysis focused on the impact of risk preferences on input use but farmers make other types of decisions, some of them possibly involving higher stakes than those implied by input application on a crop field. Discrete-choice decisions such as large investments (in large machinery or land), adoption of new technologies (such as switching from conventional to organic farming) or major changes in farming practices may be more sensitive to risk aversion due to the higher monetary amounts at stake. We believe it would be worth pursuing this type of research by assessing the impact of farmers' risk aversion on decisions that may have larger financial implications both in the short-term and in the long-term.

In the introduction we argued that this research also aimed at informing policy makers willing to regulate the use of pesticides. Since our simulations suggest the impact of risk aversion on input use could be rather moderate (except for special cases discussed in the section covering the CPT framework) and because of the high sensitivity of pesticide use to prices, we believe imposing a tax on pesticides is likely to be more effective than encouraging insurance adoption through subsidies, if the aim is to incentivize farmers to reduce the quantity of pesticides applied on the field (and pesticides are risk decreasing). ${ }^{\mathrm{xvi}}$ However, the effectiveness of a pesticide tax will largely depend on the economic conditions and in particular the level of crop prices (see also Femenia and Letort 2016, for related discussions on the incidence of a pesticide tax under varying crop prices). ${ }^{\text {xvi }}$ The comparison of various policies is beyond the scope of this article. It would require a complete cost-benefit analysis that would include not only the cost to farmers' welfare but also the estimated health and environmental benefits of reduced pesticide application. 


\section{References}

Anderson, J.R., and Dillon, J.L. (1992). Risk Analysis in Dryland Farming Systems. Farming Systems Management Series No. 2, Food and Agriculture Organization of the United Nations (FAO). FAO, Rome.

Antle, J.M. (1983). Testing the Stochastic Structure of Production: A Flexible Moment-Based Approach. Journal of Business \& Economic Statistics 1(3): 192-201.

Babcock, B.A. (2015). Using Cumulative Prospect Theory to Explain Anomalous Crop Insurance Coverage Choice. American Journal of Agricultural Economics 97(5): 1371-1384.

Barberis, N.C. (2013). Thirty Years of Prospect Theory in Economics: A Review and Assessment. Journal of Economic Perspectives 27(1): 173-196.

Böcker, T., and Finger, R. (2016). European Pesticide Tax Schemes in Comparison: An Analysis of Experiences and Developments. Sustainability 8, 378; doi:10.3390/su8040378

Bocquého, G., Jacquet, F., and Reynaud, A. (2014). Expected Utility or Prospect Theory Maximisers? Assessing Farmers' Risk Behaviour from Field-Experiment Data. European Review of Agricultural Economics 41(1): 135-172.

Bontems, P., and Thomas, A. (2000). Information Value and Risk Premium in Agricultural Production: The Case of Split Nitrogen Application for Corn. American Journal of Agricultural Economics 82(1): $59-70$.

Bougherara, D., Gassmann, X., Piet, L., and Reynaud, A. (2017). Structural Estimation of Farmers' Risk and Ambiguity Preferences: A Field Experiment. European Review of Agricultural Economics 44(5): 782-808. 
Carpentier, A. (1995). La Gestion du Risque Phytosanitaire par les Agriculteurs dans les Systèmes de Production Intensive : Une Approche Econométrique. Thèse de Doctorat. Ecole des Hautes Etudes en Sciences Sociales, France. In French.

Carpentier, A., and Letort, E. (2011). Accounting for Heterogeneity in Multicrop Micro-Econometric Models: Implications for Variable Input Demand Modeling. American Journal of Agricultural Economics 94(1): 209-224.

Carpentier, A., and Weaver, R.D. (1997). Damage Control Productivity: Why Econometrics Matters. American Journal of Agricultural Economics 79(1), 47-61.

Chavas, J.P. (2004). Risk Analysis in Theory and Practice. Elsevier, First Edition.

Chavas, J.P. (2019a). Role of Risk and Uncertainty in Agriculture in Cramer, G.L. (Ed.), Paudel, K.P. (Ed.), Schmitz, A. (Ed.), Chapter 32, The Routledge Handbook of Agricultural Economics. London: Routledge.

Chavas, J.P. (2019b). Adverse Shocks in Agriculture: The Assessment and Management of Downside Risk. Journal of Agricultural Economics 70(3): 731-748.

Chavas, J.P., and Holt, M.T. (1996). Economic Behavior under Uncertainty: A Joint Analysis of Risk Preferences and Technology. Review of Economics and Statistics 78: 329-335.

Chavas, J.P., and Nauges, C. (2020). Uncertainty, Learning and Technology Adoption in Agriculture. Applied Economic Perspectives and Policy 42(1) Special Issue: Adoption of Agricultural Innovations: 42-53.

Di Falco, S., and Chavas, J.P. (2006). Crop Genetic Diversity, Farm Productivity and the Management of Environmental Risk in Rainfed Agriculture. European Review of Agricultural Economics 33(3): 289314. 
Di Falco, S., and Chavas, J.P. (2009). On Crop Biodiversity, Risk Exposure, and Food Security in the Highlands of Ethiopia. American Journal of Agricultural Economics 91(3): 599-611.

Feder, G. (1979). Pesticides, Information, and Pest Management under Uncertainty. American Journal of Agricultural Economics 61(1): 97-103.

Femenia, F., and Letort, E. (2016). How to Significantly Reduce Pesticides Use: An Empirical Evaluation of the Impacts of Pesticides Taxation Associated with a Change in Cropping Practice. Ecological Economics 125: 27-37.

Finger, R., Möhring, N., Dalhaus, T., and Böcker, T. (2017). Revisiting Pesticide Taxation Schemes. Ecological Economics 134: 263-266.

Gardebroek, C., Chavez, M.D., and Oude Lansink, A. (2010). Analysing Production Technology and Risk in Organic and Conventional Dutch Arable Farming using Panel Data. Journal of Agricultural Economics 61(1): 60-75.

Gollier, C. (2004). The Economics of Risk and Time. Cambridge, MA: The MIT Press.

Goodwin, B.K., and Smith, V.H. (2003). An Ex Post Evaluation of the Conservation Reserve, Federal Crop Insurance, and Other Government Programs: Program Participation and Soil Erosion. Journal of Agricultural and Resource Economics 28(2): 201-216.

Goodwin, B.K., Vandeveer, M.L., and Deal, J.L. (2004). An Empirical Analysis of Acreage Effects of Participation in the Federal Crop Insurance Program. American Journal of Agricultural Economics 86(4): 1058-1077.

Harrison, G., Humphrey, S.J., and Verschoor, A. (2010). Choice under Uncertainty: Evidence from Ethiopia, India and Uganda. The Economic Journal 120(543): 80-104.

Hennessy, D.A. (1998). The Production Effects of Agricultural Income Support Policies under Uncertainty. American Journal of Agricultural Economics 80(1): 46-57. 
Horowitz, J.K., and Lichtenberg, E. (1994). Risk-Reducing and Risk-Increasing Effects of Pesticides. Journal of Agricultural Economics 45(1): 82-89.

Isik, M., and Khanna, M. (2003). Stochastic Technology, Risk Preferences, and Adoption of SiteSpecific Technologies. American Journal of Agricultural Economics 85(2): 305-317.

Just, R.E., Calvin, L., and Quiggin, J. (1999). Adverse Selection in Crop Insurance: Actuarial and Asymmetric Information Incentives. American Journal of Agricultural Economics 81(4): 834-849.

Just, R.E., and Just, D.R. (2011). Global Identification of Risk Preferences with Revealed Preference Data. Journal of Econometrics 162(1): 6-17.

Just, R.E., and Pope, R.D. (1978). Stochastic Representation of Production Functions and Econometric Implications. Journal of Econometrics 7(1): 67-86.

Just, R.E., and Pope, R.D. (1979). Production Function Estimation and Related Risk Considerations. American Journal of Agricultural Economics 61(2): 277-284.

Köszegi, B., and Rabin, M. (2007). Reference-Dependent Risk Attitudes. American Economic Review 97(4): 1047-1073.

Koundouri, P., Laukkanen, M., Myyrä, S., and Nauges, C. (2009). The Effects of EU Agricultural Policy Changes on Farmers' Risk Attitudes. European Review of Agricultural Economics 36(1): 53-77.

Koutchadé, O.P., Carpentier, A., and Femenia, F. (2018). Modeling Heterogeneous Farm Responses to European Union Biofuel Support with a Random Parameter Multicrop Model. American Journal of Agricultural Economics 100(2): 434-455.

Lence, S.H. (2000). Using Consumption and Asset Return Data to Estimate Farmers' Time Preferences and Risk Attitudes. American Journal of Agricultural Economics 82(4): 934-947. 
Lence, S.H. (2009). Joint Estimation of Risk Preferences and Technology: Flexible Utility or Futility? American Journal of Agricultural Economics 91(3): 581-598.

Lichtenberg, E., and Zilberman, D. (1986). The Econometrics of Damage Control: Why Specification Matters. American Journal of Agricultural Economics 68(2): 261-273.

Liebenehm, S., and Waibel, H. (2014). Simultaneous Estimation of Risk and Time Preferences among Small-scale Cattle Farmers in West Africa. American Journal of Agricultural Economics 96(5): 14201438.

Liu, E.M., and Huang, J. (2013). Risk Preferences and Pesticides Use by Cotton Farmers in China. Journal of Development Economics 103(0): 202-215.

Love, H.A., and Buccola, S.T. (1991). Joint Risk Preference-Technology Estimation with a Primal System. American Journal of Agricultural Economics 73(3): 765-774.

Möhring, N., Gaba, S., and Finger, R. (2019). Quantity Based Indicators Fail to Identify Extreme Pesticide Risks. Science of The Total Environment 646: 503-523.

Möhring, N., Bozzola, M., Hirsch, S. and Finger, R. (2020). Are Pesticides Risk Decreasing? The Relevance of Pesticide Indicator Choice in Empirical Analysis. Agricultural Economics, DOI: 10.1111/agec.12563, published online.

Nguyen, Q. (2011). Does Nurture Matter: Theory and Experimental Investigation on the Effect of Working Environment on Risk and Time Preferences. Journal of Risk and Uncertainty 43(3): 245-270.

Nguyen, Q., and Leung, P. (2010). How Nurture Can Shape Preferences: An Experimental Study on Risk Preferences of Vietnamese Fishers. Environment and Development Economics 15(5): 609-631.

Pannell, D.J. (1991). Pests and Pesticides, Risk and Risk Aversion. Agricultural Economics 5(4): 361383. 
Pannell, D.J. (1995). Optimal Herbicide Strategies for Weed Control under Risk Aversion. Review of Agricultural Economics 17(3): 337-350.

Pannell, D.J., Malcolm, B. and R.S. Kingwell (2000). Are We Risking Too Much? Perspectives on Risk in Farm Modelling. Agricultural Economics 23(1): 69-78.

Pannell, D.J. (2006). Flat Earth Economics: The Far-Reaching Consequences of Flat Payoff Functions in Economic Decision Making. Review of Agricultural Economics 28(4): 553-566.

Pope, R.D., LaFrance, J.T. and Just, R.E. (2011). Agricultural Arbitrage and Risk Preferences. Journal of Econometrics 162(1): 35-43.

Prelec, D. (1998). The Probability Weighting Function. Econometrica 66(3): 497-527.

Quiggin, J., Karagiannis, G., and Stanton, J. (1993). Crop Insurance and Crop Production: An Empirical Study of Moral Hazard and Adverse Selection. Australian Journal of Agricultural Economics 37(2): 95113.

Read, D., Loewenstein, G., and Rabin, M. (1999). Choice Bracketing. Journal of Risk and Uncertainty 19(1): 171-197.

Saha, A., Shumway, C.R., and Talpaz, H. (1994). Joint Estimation of Risk Preference Structure and Technology using Expo-Power Utility. American Journal of Agricultural Economics 76(2): 173-184.

Sckokai, P., and Moro, D. (2006). Modeling the Reforms of the Common Agricultural Policy for Arable Crops under Uncertainty. American Journal of Agricultural Economics 88(1): 43-56.

Serra, T., Zilberman, D., Goodwin, B.K., and Featherstone, A. (2006). Effects of Decoupling on the Mean and Variability of Output. European Review of Agricultural Economics 33(3): 269-288.

Serra, T., Zilberman, D., and Gil, J.M. (2008). Farms' Technical Inefficiencies in the Presence of Government Programs. The Australian Journal of Agricultural and Resource Economics 52(1): 57-76. 
Skevas, T., Oude Lansink, A.G.J.M., and Stefanou, S.E. (2013). Designing the Emerging EU Pesticide Policy: A Literature Review. NJAS - Wageningen Journal of Life Sciences Vol 64-65: 95-103.

Smith, V.H., and Goodwin, B.K. (1996). Crop Insurance, Moral Hazard, and Agricultural Chemical Use. American Journal of Agricultural Economics 78(2): 428-438.

Tanaka, T., Camerer, C.F., and Nguyen, Q. (2010). Risk and Time Preferences: Linking Experimental and Household Survey Data from Vietnam. American Economic Review 100(1): 557-571.

Tversky, A., and Kahneman, D. (1992). Advances in Prospect Theory: Cumulative Representation of Uncertainty. Journal of Risk and Uncertainty 5(4): 297-323.

Verschoor, A., D'Exelle, B., and Perez-Viana, B. (2016). Lab and Life: Does Risky Choice Behaviour Observed in Experiments Reflect that in the Real World? Journal of Economic Behavior \& Organization 128: 134-148.

Weber, J.G., Key, N., and O’Donoghue, E. (2016). Does Federal Crop Insurance Make Environmental Externalities from Agriculture Worse? Journal of the Association of Environmental and Resource Economists 3(3): 707-742.

Wu, J. (1999). Crop Insurance, Acreage Decisions, and Nonpoint-Source Pollution. American Journal of Agricultural Economics 81(2): 305-320. 


\section{List of Tables}

Table 1. Optimal Input Use, Risk Premium (RP), and Certainty Equivalent (CE) under Various Levels of Relative Risk Aversion

\begin{tabular}{|c|c|c|c|c|c|}
\hline & \multirow{2}{*}{$\begin{array}{c}\begin{array}{c}\text { Risk } \\
\text { neutrality }\end{array} \\
r_{r}=0\end{array}$} & \multicolumn{4}{|c|}{ Risk aversion } \\
\hline & & $r_{r}=1$ & $r_{r}=2$ & $r_{r}=3$ & $r_{r}=4$ \\
\hline Optimal input use (EUR) & 264 & 268 & 273 & 279 & 285 \\
\hline Input used for self-insurance (\%) & 0.0 & 1.5 & 3.3 & 5.4 & 7.4 \\
\hline $\mathrm{RP}^{*}(\mathrm{EUR})$ & 0 & 17 & 34 & 52 & 71 \\
\hline CE* (EUR) & 1,115 & 1,098 & 1,081 & 1,063 & 1,044 \\
\hline Change in CE $(\%)^{b}$ & - & -1.5 & -3.0 & -4.6 & -6.3 \\
\hline
\end{tabular}

Note: Initial wealth $w_{0}$ is set at 500 EUR. RP*: Risk Premium at the optimum; CE*: Certainty Equivalent at the optimum. The CE includes the initial wealth $w_{0}$.

${ }^{\text {a }}$ Computed as $\left(x^{*}-x_{0}^{*}\right) / x^{*} \times 100 ;{ }^{b}$ Computed as $\left(C E^{*}-E(w)\right) / E(w) \times 100$. 
Table 2. Sensitivity of Input Use to Levels of Relative Risk Aversion and Price Ratios

\begin{tabular}{|c|c|c|c|c|c|c|}
\hline \multirow[b]{2}{*}{ Price ratio } & & \multirow{2}{*}{$\begin{array}{c}\text { Risk } \\
\text { neutrality } \\
r_{r}=0\end{array}$} & \multirow[b]{2}{*}{$r_{r}=1$} & \multicolumn{3}{|c|}{ Risk aversion } \\
\hline & & & & $r_{r}=2$ & $r_{r}=3$ & $r_{r}=4$ \\
\hline \multirow[t]{4}{*}{1 to 13} & Input use (EUR) & 335 & 340 & 346 & 352 & 359 \\
\hline & Self-Insur. (\%) & 0.0 & 1.5 & 3.2 & 4.8 & 6.7 \\
\hline & $\mathrm{RP}^{*}(\mathrm{EUR})$ & 0 & 19 & 39 & 60 & 82 \\
\hline & $\Delta \mathrm{CE}(\%)$ & - & -1.5 & -3.1 & -4.7 & -6.4 \\
\hline \multirow{4}{*}{$\begin{array}{l}1 \text { to } 11 \\
\text { (benchmark) }\end{array}$} & Input use (EUR) & 264 & 268 & 273 & 279 & 285 \\
\hline & Self-Insur. (\%) & 0.0 & 1.5 & 3.3 & 5.4 & 7.4 \\
\hline & RP* (EUR) & 0 & 17 & 34 & 52 & 71 \\
\hline & $\Delta$ CE (\%) & - & -1.5 & -3.0 & -4.6 & -6.3 \\
\hline \multirow[t]{4}{*}{1 to 9} & Input use (EUR) & 198 & 202 & 206 & 210 & 215 \\
\hline & Self-Insur. (\%) & 0.0 & 2.0 & 3.9 & 5.7 & 7.9 \\
\hline & RP* (EUR) & 0 & 14 & 28 & 42 & 58 \\
\hline & $\Delta \mathrm{CE}(\%)$ & - & -1.4 & -2.9 & -4.4 & -6.0 \\
\hline \multirow[t]{4}{*}{1 to 7} & Input use (EUR) & 138 & 141 & 144 & 147 & 151 \\
\hline & Self-Insur. (\%) & 0.0 & 2.1 & 4.2 & 6.1 & 8.6 \\
\hline & RP* (EUR) & 0.0 & 10 & 21 & 32 & 43 \\
\hline & $\Delta \mathrm{CE}(\%)$ & - & -1.2 & -2.5 & -3.9 & -5.2 \\
\hline
\end{tabular}


Table 3. Sensitivity of Input Use to Levels of Relative Risk Aversion and Parameters of the Mean Yield Function

\begin{tabular}{|c|c|c|c|c|c|c|}
\hline \multirow[b]{2}{*}{ Mean yield function } & & \multirow{2}{*}{$\begin{array}{c}\text { Risk neutrality } \\
r_{r}=0\end{array}$} & \multicolumn{4}{|c|}{ Risk aversion } \\
\hline & & & $r_{r}=1$ & $r_{r}=2$ & $r_{r}=3$ & $r_{r}=4$ \\
\hline \multirow[t]{4}{*}{$f(x)=15 x^{0.20}$} & Input use (EUR) & 79 & 87 & 97 & 110 & 124 \\
\hline & Self-Insurance (\%) & 0.0 & 9.2 & 18.6 & 28.2 & 36.3 \\
\hline & $\mathrm{RP} *(E U R)$ & 0 & 30 & 64 & 104 & 152 \\
\hline & $\Delta \mathrm{CE}(\%)$ & - & -3.7 & -7.9 & -12.8 & -18.8 \\
\hline \multirow[t]{4}{*}{$f(x)=15 x^{0.25}$} & Input use (EUR) & 143 & 149 & 156 & 164 & 173 \\
\hline & Self-Insurance (\%) & 0.0 & 4.0 & 8.3 & 12.8 & 17.3 \\
\hline & RP* (EUR) & 0 & 23 & 48 & 75 & 104 \\
\hline & $\Delta \mathrm{CE}(\%)$ & - & -2.5 & -5.1 & -8.0 & -11.2 \\
\hline & Input use (EUR) & 264 & 268 & 273 & 279 & 285 \\
\hline \multirow{3}{*}{ (benchmark) } & Self-Insurance (\%) & 0.0 & 1.5 & 3.3 & 5.4 & 7.4 \\
\hline & RP* (EUR) & 0 & 17 & 34 & 52 & 71 \\
\hline & $\Delta \mathrm{CE}(\%)$ & - & -1.5 & -3.0 & -4.6 & -6.3 \\
\hline \multirow[t]{4}{*}{$f(x)=10 x^{0.30}$} & Input use (EUR) & 148 & 155 & 164 & 175 & 187 \\
\hline & Self-Insurance (\%) & 0.0 & 4.5 & 9.8 & 15.4 & 20.9 \\
\hline & $\mathrm{RP}^{*}(\mathrm{EUR})$ & 0 & 25 & 53 & 85 & 121 \\
\hline & $\Delta \mathrm{CE}(\%)$ & - & -3.0 & -6.3 & -10.1 & -14.4 \\
\hline \multirow[t]{4}{*}{$f(x)=18 x^{0.30}$} & Input use (EUR) & 342 & 346 & 350 & 354 & 358 \\
\hline & Self-Insurance (\%) & 0.0 & 1.2 & 2.3 & 3.4 & 4.5 \\
\hline & $\mathrm{RP}^{*}(\mathrm{EUR})$ & 0 & 13 & 27 & 41 & 56 \\
\hline & $\Delta \mathrm{CE}(\%)$ & - & -1.0 & -2.1 & -3.2 & -4.3 \\
\hline
\end{tabular}

Note: The pesticides-crop price ratio is 1 to 11 and initial wealth $w_{0}=500$ EUR. 
Table 4. Optimal Quantity of Input Use and Risk Premium under Various CPT Scenarios

\begin{tabular}{|c|c|c|c|c|c|}
\hline & $\begin{array}{c}\text { CPT } \\
\text { Scenario (0) } \\
(T-K, 1992)^{a} \\
\end{array}$ & $\begin{array}{c}\text { Scenario (1) } \\
\text { Stronger } \\
\text { distortion of } \\
\text { prob. in losses }\end{array}$ & $\begin{array}{c}\text { Scenario (2) } \\
\text { Stronger risk } \\
\text { aversion in } \\
\text { gains }\end{array}$ & $\begin{array}{c}\text { Scenario (3) } \\
(1)+(2)\end{array}$ & $\begin{array}{l}\text { Scenario (4) } \\
\text { (3) + stronger } \\
\text { loss aversion }\end{array}$ \\
\hline & \multirow[t]{2}{*}{$r r^{+}=r r^{-}=0.12$} & \multirow[t]{2}{*}{$r r^{+}=r r^{-}=0.12$} & $r r^{+}=0.88$ & $r r^{+}=0.88$ & $r r^{+}=0.88$ \\
\hline & & & $r r^{-}=0.12$ & $r r^{-}=0.12$ & $r r^{-}=0.12$ \\
\hline & $\lambda=2.25$ & $\lambda=2.25$ & $\lambda=2.25$ & $\lambda=2.25$ & $\lambda=3.50$ \\
\hline & $\gamma=0.61$ & $\gamma=0.61$ & $\gamma=0.61$ & $\gamma=0.61$ & $\gamma=0.61$ \\
\hline & $\delta=0.69$ & $\delta=0.30$ & $\delta=0.69$ & $\delta=0.30$ & $\delta=0.30$ \\
\hline \multicolumn{6}{|c|}{ Reference point $=0 €$} \\
\hline$x^{*}(\Delta, \%)^{\mathrm{b}}$ & $272(2.9 \%)$ & $272(2.9 \%)$ & $281(6.0 \%)$ & $281(6.0 \%)$ & $281(6.0 \%)$ \\
\hline $\mathrm{RP}^{*}$ (EUR) & 54 & 54 & 85 & 85 & 85 \\
\hline \multicolumn{6}{|c|}{ Reference point $=$ median profit ${ }^{c}$} \\
\hline $\mathrm{X}^{*}(\Delta, \%)$ & 275 (4.0\%) & 275 (4.0\%) & $291(9.3 \%)$ & $320(17.5 \%)$ & 324 (18.5\%) \\
\hline $\mathrm{RP}^{*}$ (EUR) & 47 & 30 & 84 & 62 & 63 \\
\hline \multicolumn{6}{|c|}{ Reference point $=$ maximum profit ${ }^{c}$} \\
\hline$x^{*}(\Delta, \%)$ & $274(3.6 \%)$ & $275(4.0 \%)$ & 290 (9.0\%) & $318(17.0 \%)$ & $323(18.3 \%)$ \\
\hline RP* (EUR) & 41 & 20 & 77 & 51 & 52 \\
\hline
\end{tabular}

Note: The pesticides-crop price ratio is 1 to 11 and initial wealth $w_{0}=500$ EUR.

${ }^{a}$ In Tversky and Kahneman (1992), the exponent of the value function is denoted $\alpha$ in the gain domain and $\beta$ in the loss domain. In our case the exponent of the value function is $(1-r r+)$ in the gain domain and $(1-r r-)$ in the loss domain. Parameters $\alpha$ and $\beta$ are estimated at 0.88 in Tversky and Kahneman (1992), which corresponds to $r^{+}=r r^{-}=1-0.88=0.12$.

${ }^{b} \Delta$ measures the quantity of input use that is induced by the aversion to risk. It is computed as $\left(x^{*}-x_{0}^{*}\right) / x^{*} \times 100$, with $x_{0}{ }^{*}=264$ being the optimal input use under risk neutrality.

${ }^{c}$ The median and maximum profits are 1,102 EUR and 1,115 EUR respectively. 
Table 5. Sensitivity of Input Use and Risk Premium to Pesticides-Crop Price Ratio - CPT Framework

\begin{tabular}{|c|c|c|c|c|c|}
\hline & $\begin{array}{c}\text { CPT } \\
\text { Scenario (0) } \\
(T-K, 1992)\end{array}$ & $\begin{array}{c}\text { Scenario (1) } \\
\text { Stronger } \\
\text { distortion of } \\
\text { prob. in losses }\end{array}$ & $\begin{array}{l}\text { Scenario (2) } \\
\text { Stronger risk } \\
\text { aversion in } \\
\text { gains }\end{array}$ & $\begin{array}{c}\text { Scenario (3) } \\
(1)+(2)\end{array}$ & $\begin{array}{l}\text { Scenario (4) } \\
\text { (3) + stronger } \\
\text { loss aversion }\end{array}$ \\
\hline & \multirow[t]{2}{*}{$r r^{+}=r r^{-}=0.12$} & \multirow[t]{2}{*}{$r r^{+}=r r^{-}=0.12$} & $r r^{+}=0.88$ & $r r^{+}=0.88$ & $r r^{+}=0.88$ \\
\hline & & & $r r^{-}=0.12$ & $r r^{-}=0.12$ & $r r^{-}=0.12$ \\
\hline & $\lambda=2.25$ & $\lambda=2.25$ & $\lambda=2.25$ & $\lambda=2.25$ & $\lambda=3.50$ \\
\hline & $\gamma=0.61$ & $\gamma=0.61$ & $\gamma=0.61$ & $\gamma=0.61$ & $\gamma=0.61$ \\
\hline & $\delta=0.69$ & $\delta=0.30$ & $\delta=0.69$ & $\delta=0.30$ & $\delta=0.30$ \\
\hline \multicolumn{6}{|c|}{ Price ratio $=1$ to 11} \\
\hline$x^{*}(\Delta, \%)$ & $275(4.0 \%)$ & 275 (4.0\%) & 291 (9.3\%) & $320(17.5 \%)$ & $324(18.5 \%)$ \\
\hline RP* (EUR) & 47 & 30 & 84 & 62 & 63 \\
\hline \multicolumn{6}{|c|}{ Price ratio $=1$ to 13} \\
\hline $\mathrm{x}^{*}(\Delta, \%)$ & $347(3.5 \%)$ & $348(3.7 \%)$ & $366(8.5 \%)$ & $>400(>16 \%)$ & $>400(>16 \%)$ \\
\hline RP* (EUR) & 59 & 42 & 104 & - & - \\
\hline \multicolumn{6}{|c|}{ Price ratio $=1$ to 7} \\
\hline$x^{*}(\Delta, \%)$ & $146(5.5 \%)$ & $146(5.5 \%)$ & $158(12.7 \%)$ & $174(20.7 \%)$ & $178(22.5 \%)$ \\
\hline $\mathrm{RP}^{*}$ (EUR) & 40 & 33 & 66 & 55 & 56 \\
\hline
\end{tabular}

Note: The reference point is the median profit and initial wealth $w_{0}=500$ EUR.

${ }^{a}$ The median profit when the price ratio is 1 to 11,1 to 13 , and 1 to 7 , is 1,102 EUR, 1,256 EUR, and 797 EUR, respectively. 


\section{List of Figures}

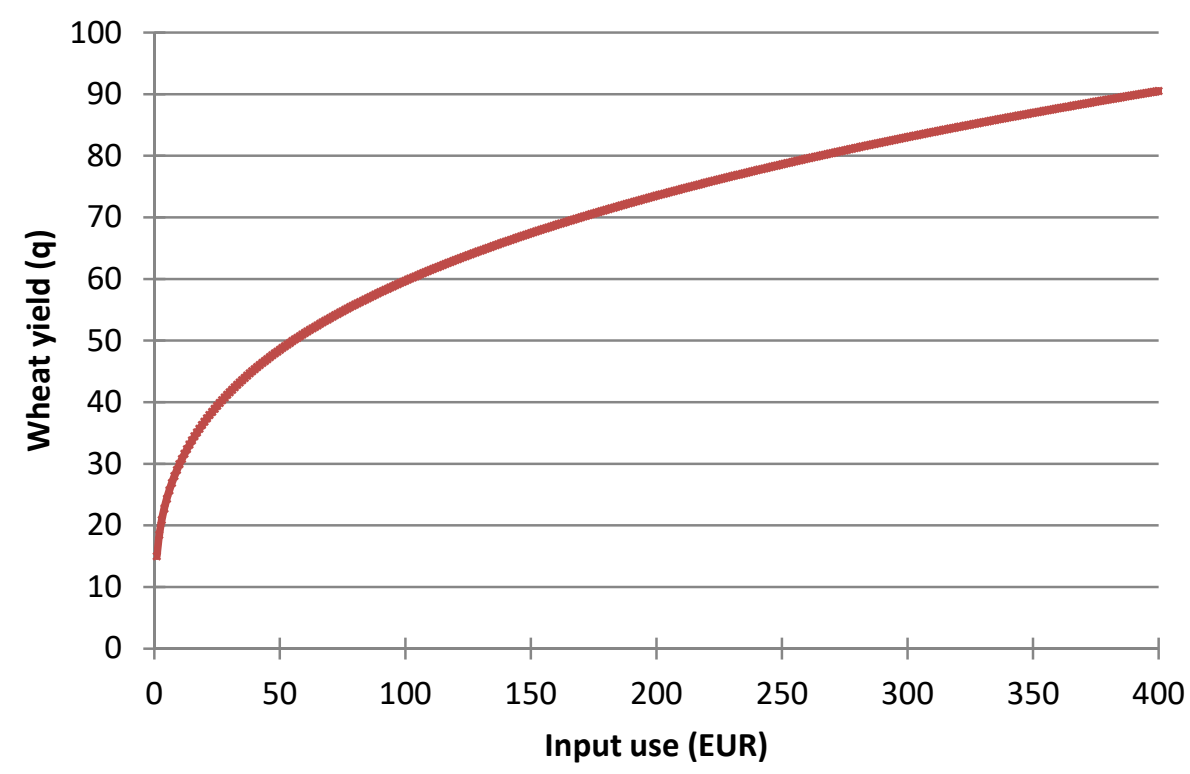

Figure 1. Production function for a one-hectare field $(\varepsilon=0)$ 


\section{Appendix}

A1. Review of Technology Parameters: Elasticities of Mean Output and Output Variance to Input Use

We report below estimates from the literature of the elasticity of mean output and output variance to input use, for studies that have estimated production functions and measured output in physical quantities. All these estimates are for arable farms producing crops.

\begin{tabular}{|c|c|c|c|}
\hline Article & Country and inputs & $\begin{array}{c}\text { Elasticity of mean } \\
\text { output }\end{array}$ & $\begin{array}{c}\text { Elasticity of output } \\
\text { variance }\end{array}$ \\
\hline Just and Pope (1979) & $\begin{array}{l}\text { Country: US } \\
\text { Input: fertilizers }\end{array}$ & $0.3-0.4$ & $0.1-0.2$ \\
\hline $\begin{array}{l}\text { Gardebroek, Chavez } \\
\text { and Oude Lansink } \\
\text { (2010) }\end{array}$ & $\begin{array}{l}\text { Country: Netherlands } \\
\text { Input: herbicides and } \\
\text { pesticides }\end{array}$ & $\begin{array}{c}0.23 \text { (for conventional } \\
\text { farms) }\end{array}$ & $\begin{array}{c}0.21 \text { (but not } \\
\text { statistically significant) }\end{array}$ \\
\hline Koundouri et al. (2009) & $\begin{array}{l}\text { Country: Finland } \\
\text { Inputs: fertilizers and } \\
\text { plant protection }\end{array}$ & $\begin{array}{c}0.50 \text { for plant } \\
\text { protection } \\
0.77 \text { for fertilizers }\end{array}$ & $\begin{array}{c}-0.05 \text { for plant } \\
\text { protection } \\
-0.02 \text { for fertilizers }\end{array}$ \\
\hline $\begin{array}{l}\text { Femenia and Letort } \\
\text { (2016) }\end{array}$ & $\begin{array}{l}\text { Country: France } \\
\text { Inputs: fertilizers and } \\
\text { pesticides }\end{array}$ & $\begin{array}{l}0.1 \text { for both fertilizers } \\
\text { and pesticides }\end{array}$ & - \\
\hline
\end{tabular}


A2. Review of Relative Risk Aversion Parameters Derived from Expected Utility Models

\begin{tabular}{|c|c|c|}
\hline Authors & Sample & $\begin{array}{l}\text { Coefficient of relative } \\
\text { risk aversion }\end{array}$ \\
\hline Bontems and Thomas (2000) & $\begin{array}{l}\text { Corn plots from US Midwest } \\
1990-1992\end{array}$ & 3.7 \\
\hline Chavas and Holt (1996) & $\begin{array}{l}\text { US aggregate corn and soybean } \\
\text { acreage decisions } \\
\text { 1954-1985 }\end{array}$ & {$[1.4-6.8]$} \\
\hline Isik and Khanna (2003) & $\begin{array}{l}\text { Field-level data (99 fields) from } \\
\text { Illinois (US) } \\
\text { 1993-1994 }\end{array}$ & 1.5 \\
\hline Lence (2000) & $\begin{array}{l}\text { US aggregate data } \\
\text { 1934-1994 }\end{array}$ & {$[1.1-2.5]$} \\
\hline Love and Buccola (1991) & $\begin{array}{l}\text { Farm data on corn and soybean } \\
\text { production, Iowa (USA) }\end{array}$ & {$[2.4-18.8]$} \\
\hline Pope, LaFrance and Just (2011) & $\begin{array}{l}\text { State-level data on net returns } \\
\text { and acreages, } 8 \text { US States }\end{array}$ & 0.4 \\
\hline Saha, Shumway and Talpaz (1994) & $\begin{array}{l}\text { Farm-level data for wheat farms } \\
\text { in Kansas (US), 1979-1982 }\end{array}$ & {$[3.8-5.4]$} \\
\hline Sckokai and Moro (2006) & $\begin{array}{l}\text { Farm-level data from Italy, } \\
\text { 1993-1999 }\end{array}$ & {$[0-5.5]$} \\
\hline
\end{tabular}


A3. Sensitivity of the Optimal Input Use to the Mean Function

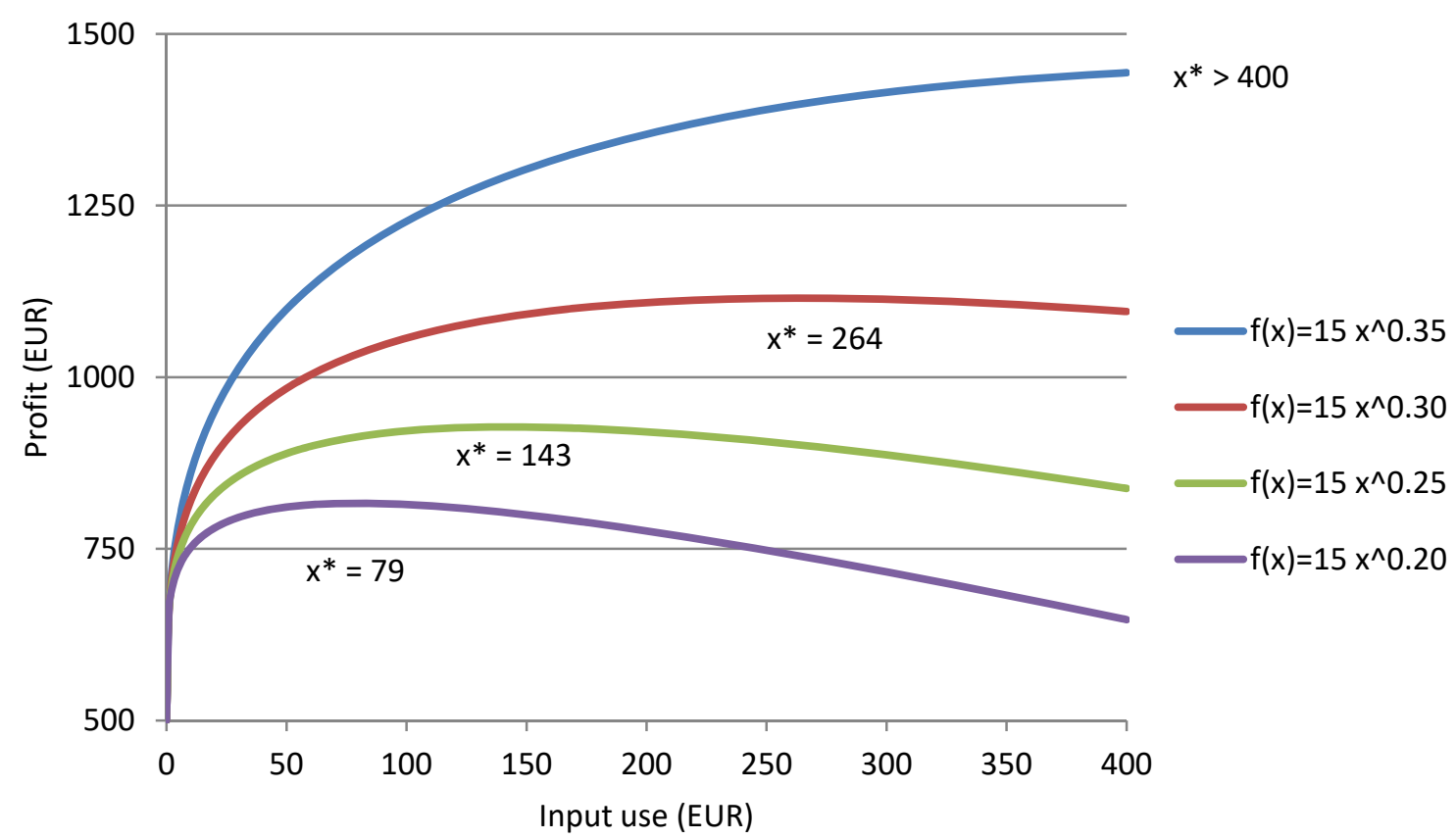

Figure A3-1. Profit functions for different mean production functions (price ratio $=1$ to $11, \varepsilon=0$ )

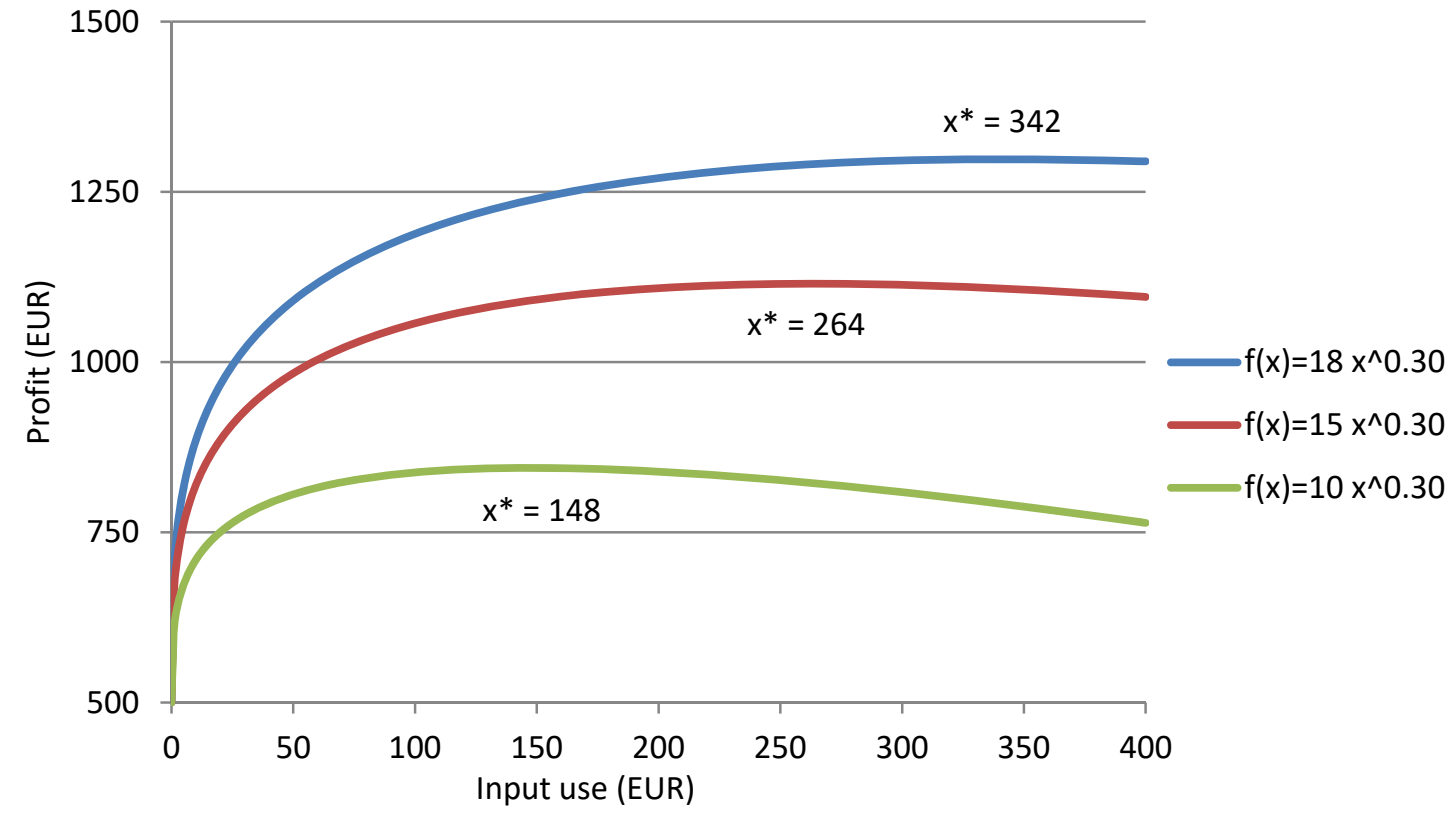

Figure A3-2. Profit functions for different mean production functions (price ratio $=1$ to $11, \varepsilon=0$ ) 
A4. Sensitivity of Input Use and Risk Premium to Levels of Relative Risk Aversion and Parameters of the Risk Function

\begin{tabular}{llccccc}
\hline \multirow{3}{*}{ Risk function } & & Risk neutrality & \multicolumn{5}{c}{ Risk aversion } \\
& & $r_{r}=0$ & $r_{r}=1$ & $r_{r}=2$ & $r_{r}=3$ & $r_{r}=4$ \\
& & & & & & \\
$g(x)=20 x^{-0.1}$ & Input use (EUR) & 264 & 266 & 268 & 270 & 272 \\
& Self-Insurance (\%) & 0.0 & 0.8 & 1.5 & 2.2 & 2.9 \\
& RP* (EUR) & 0 & 7 & 15 & 22 & 30 \\
& $\Delta$ CE (\%) & - & -0.6 & -1.3 & -2.0 & -2.6 \\
& & & & & & \\
$g(x)=40 x^{-0.1}$ & Input use (EUR) & 264 & 273 & 283 & 295 & 309 \\
& Self-Insurance (\%) & 0.0 & 3.3 & 6.7 & 10.5 & 14.6 \\
& RP* (EUR) & 0 & 30 & 63 & 100 & 142 \\
& $\Delta$ CE (\%) & - & -2.7 & -5.7 & -9.0 & -12.7 \\
& & & & & & \\
$g(x)=30 x^{-0.1}$ & Input use (EUR) & $\mathbf{2 6 4}$ & $\mathbf{2 6 8}$ & $\mathbf{2 7 3}$ & $\mathbf{2 7 9}$ & $\mathbf{2 8 5}$ \\
& Self-Insurance (\%) & $\mathbf{0 . 0}$ & $\mathbf{1 . 5}$ & $\mathbf{3 . 3}$ & $\mathbf{5 . 4}$ & $\mathbf{7 . 4}$ \\
& RP* (EUR) & $\mathbf{0}$ & $\mathbf{1 7}$ & $\mathbf{3 4}$ & $\mathbf{5 2}$ & $\mathbf{7 1}$ \\
& $\Delta$ CE (\%) & - & $-\mathbf{1 . 5}$ & $-\mathbf{3 . 0}$ & $-\mathbf{4 . 6}$ & $-\mathbf{- 6 . 3}$ \\
& & & & & & \\
& Input use (EUR) & 264 & 267 & 270 & 273 & 276 \\
& Self-Insurance (\%) & 0.0 & 1.1 & 2.2 & 3.3 & 4.3 \\
& RP* (EUR) & 0 & 5 & 11 & 16 & 21 \\
& $\Delta$ CE (\%) & - & -0.5 & -1.0 & -1.4 & -1.9 \\
\hline
\end{tabular}

Note: The pesticides-crop price ratio is 1 to 11 and initial wealth $w_{0}=500$ EUR. 


\begin{tabular}{|c|c|c|c|c|c|c|}
\hline \multirow[b]{2}{*}{ Initial wealth } & & \multirow{2}{*}{$\begin{array}{c}\text { Risk neutrality } \\
r_{r}=0\end{array}$} & \multicolumn{4}{|c|}{ Risk aversion } \\
\hline & & & $r_{r}=1$ & $r_{r}=2$ & $r_{r}=3$ & $r_{r}=4$ \\
\hline 500 EUR & Input use (EUR) & 264 & 268 & 273 & 279 & 285 \\
\hline \multirow[t]{3}{*}{ (benchmark) } & Self-Insurance (\%) & 0.0 & 1.5 & 3.3 & 5.4 & 7.4 \\
\hline & RP* (EUR) & 0 & 17 & 34 & 52 & 71 \\
\hline & $\Delta \mathrm{CE}(\%)$ & - & -1.5 & -3.0 & -4.6 & -6.3 \\
\hline \multirow[t]{4}{*}{ 1,000 EUR } & Input use (EUR) & 264 & 267 & 270 & 273 & 277 \\
\hline & Self-Insurance (\%) & 0.0 & 1.1 & 2.2 & 3.3 & 4.7 \\
\hline & $\mathrm{RP}^{*}(\mathrm{EUR})$ & 0 & 11 & 23 & 34 & 46 \\
\hline & $\Delta \mathrm{CE}(\%)$ & - & -0.7 & -1.4 & -2.1 & -2.8 \\
\hline \multirow[t]{4}{*}{1,500 EUR } & Input use (EUR) & 264 & 266 & 268 & 271 & 273 \\
\hline & Self-Insurance (\%) & 0.0 & 0.8 & 1.5 & 2.6 & 3.3 \\
\hline & $\mathrm{RP} *(\mathrm{EUR})$ & 0 & 8 & 17 & 26 & 34 \\
\hline & $\Delta \mathrm{CE}(\%)$ & - & -0.4 & -0.8 & -1.2 & -1.6 \\
\hline \multirow[t]{4}{*}{ 5,000 EUR } & Input use (EUR) & 264 & 264 & 265 & 266 & 267 \\
\hline & Self-Insurance (\%) & 0.0 & 0 & 0.4 & 0.8 & 1.1 \\
\hline & RP* (EUR) & 0 & 3 & 6 & 10 & 13 \\
\hline & $\Delta \mathrm{CE}(\%)$ & - & -0.1 & -0.1 & -0.2 & -0.2 \\
\hline
\end{tabular}

Note: The pesticides-crop price ratio is 1 to 11 . The production function is the same as the one used in the benchmark scenario. 


\section{A6. Review of Parameters Derived from CPT Models}

\begin{tabular}{|c|c|c|}
\hline Authors, Sample & Specification & Parameter estimates \\
\hline $\begin{array}{l}\text { Tversky and Kahneman } \\
\text { (1992) } \\
25 \text { students }\end{array}$ & $\begin{array}{l}\text { CRRA utility function } \\
\text { No preference reversal } \alpha^{+}=\alpha^{-}=\alpha \\
\text { Loss aversion } \lambda \\
\text { KT probability weighting function } \gamma^{+} \neq \gamma^{-}\end{array}$ & $\begin{array}{c}\hat{\alpha}=\widehat{\alpha^{+}}=\widehat{\alpha^{-}}=0.88 \\
\text { (farmers are risk averse) } \\
\hat{\lambda} \approx 2.25 \\
(\text { farmers are loss averse) } \\
\widehat{\gamma^{+}} \approx 0.61 ; \widehat{\gamma^{-}} \approx 0.69 \\
\text { (less probability distortion in losses } \\
\text { than in gains) }\end{array}$ \\
\hline $\begin{array}{l}\text { Tanaka, Camerer and } \\
\text { Nguyen (2010) } \\
181 \text { villagers, Vietnam }\end{array}$ & $\begin{array}{l}\text { CRRA utility function } \\
\text { No preference reversal } \alpha^{+}=\alpha^{-}=\alpha \\
\text { Loss aversion } \lambda \\
\text { Prelec probability weighting function } \gamma^{+}=\gamma^{-}=\gamma\end{array}$ & $\begin{array}{l}\hat{\alpha}=0.60 \\
\hat{\lambda}=3.47 \\
\hat{\gamma}=0.74\end{array}$ \\
\hline $\begin{array}{l}\text { Nguyen and Leung } \\
(2010) \\
103 \text { fishermen, } \\
\text { Vietnam }\end{array}$ & $\begin{array}{l}\text { CRRA utility function } \\
\text { No preference reversal } \alpha^{+}=\alpha^{-}=\alpha \\
\text { Loss aversion } \lambda \\
\text { Prelec probability weighting function } \gamma^{+}=\gamma^{-}=\gamma\end{array}$ & $\begin{array}{l}\hat{\alpha}=0.62 \\
\hat{\lambda}=2.63 \\
\hat{\gamma}=0.75\end{array}$ \\
\hline \multirow{2}{*}{$\begin{array}{l}\text { Harrison, Humphrey, } \\
\text { Verschoor (2010) } \\
531 \text { villagers, Ethiopia, } \\
\text { India and Uganda }\end{array}$} & $\begin{array}{l}\text { CRRA utility function } \\
\text { No loss aversion (gains only) } \\
\text { KT probability weighting function } \gamma\end{array}$ & $\begin{array}{l}\hat{\alpha}=0.54 \\
\hat{\gamma}=1.38\end{array}$ \\
\hline & $\begin{array}{l}\text { CRRA utility function } \\
\text { No loss aversion (gains only in the experiment) } \\
\text { Prelec probability weighting function } \gamma \text { (and additional } \\
\text { scale parameter } \eta \text { ) }\end{array}$ & $\begin{array}{l}\hat{\alpha}=0.50 \\
\hat{\gamma}=0.96 \\
\hat{\eta}=1.20\end{array}$ \\
\hline $\begin{array}{l}\text { Nguyen (2011) } \\
181 \text { fishermen, } \\
\text { Vietnam }\end{array}$ & $\begin{array}{l}\text { CRRA utility function } \\
\text { No preference reversal } \alpha^{+}=\alpha^{-}=\alpha \\
\text { Loss aversion } \lambda \\
\text { Prelec probability weighting function } \gamma^{+}=\gamma^{-}=\gamma\end{array}$ & $\begin{array}{l}\hat{\alpha}=1.01 \\
\hat{\lambda}=3.26 \\
\hat{\gamma}=0.96\end{array}$ \\
\hline $\begin{array}{l}\text { Liu and Huang (2013) } \\
320 \text { cotton farmers, } \\
\text { China }\end{array}$ & $\begin{array}{l}\text { CRRA utility function } \\
\text { No preference reversal } \alpha^{+}=\alpha^{-}=\alpha \\
\text { Loss aversion } \lambda \\
\text { Prelec probability weighting function } \gamma^{+}=\gamma^{-}=\gamma\end{array}$ & $\begin{array}{l}\hat{\alpha}=0.52 \\
\hat{\lambda}=3.47 \\
\hat{\gamma}=0.69\end{array}$ \\
\hline $\begin{array}{l}\text { Bocquého et al. (2014) } \\
\text { Farmers, France }\end{array}$ & $\begin{array}{l}\text { CRRA utility function } \\
\text { No preference reversal } \alpha^{+}=\alpha^{-}=\alpha \\
\text { Loss aversion } \lambda \\
\text { Prelec probability weighting function } \gamma^{+}=\gamma^{-}=\gamma\end{array}$ & $\begin{array}{l}\hat{\alpha}=0.28 \\
\hat{\lambda}=2.28 \\
\hat{\gamma}=0.66\end{array}$ \\
\hline $\begin{array}{l}\text { Liebenehm and Waibel } \\
\text { (2014) } \\
211 \text { cattle farmers, } \\
\text { Mali and Burkina Faso }\end{array}$ & $\begin{array}{l}\text { CRRA utility function } \\
\text { No preference reversal } \alpha^{+}=\alpha^{-}=\alpha \\
\text { Loss aversion } \lambda \\
\text { Prelec probability weighting function } \gamma^{+}=\gamma^{-}=\gamma\end{array}$ & $\begin{array}{l}\hat{\alpha}=0.11 \\
\hat{\lambda}=1.35 \\
\hat{\gamma}=0.13\end{array}$ \\
\hline $\begin{array}{l}\text { Bougherara et al. } \\
\text { (2017) } \\
197 \text { crop farmers, } \\
\text { France }\end{array}$ & $\begin{array}{l}\text { CRRA utility function } \\
\text { No preference reversal } \alpha^{+}=\alpha^{-}=\alpha \\
\text { Loss aversion } \lambda \\
\text { KT probability weighting function } \gamma^{+} \neq \gamma^{-}\end{array}$ & $\begin{array}{c}\hat{\alpha}=0.61 \\
\hat{\lambda}=1.37 \\
\widehat{\gamma^{+}=0.79} ; \widehat{\gamma^{-}}=0.84\end{array}$ \\
\hline
\end{tabular}


CRRA utility function

No preference reversal $\alpha^{+}=\alpha^{-}=\alpha$

Loss aversion $\lambda$

Prelec probability weighting function $\gamma^{+} \neq \gamma^{-}$ $\hat{\alpha}=0.63$

$\hat{\lambda}=1.38$

$\hat{\gamma}^{+}=0.81 ; \hat{\gamma}^{-}=0.89$

$\hat{\alpha}^{+}=0.60 ; \hat{\alpha}^{-}=0.66$

$\hat{\gamma}^{+}=0.79 ; \hat{\gamma}^{-}=0.84$

CRRA utility function

Preference reversal $\alpha^{+} \neq \alpha^{-}$

No loss aversion

KT probability weighting function $\gamma^{+} \neq \gamma^{-}$

Note: KT is for Kahneman and Tversky. See Prelec (1998) for Prelec's probability weighting function. 


\section{Endnotes}

${ }^{i}$ Some empirical evidence of pesticides reducing production risk were found in Di Falco and Chavas (2006) using data from durum wheat farms in Sicily (Italy) and in Koundouri et al. (2009) on a panel of Finnish crop farms but Serra et al. (2006) and Serra, Zilberman, and Gil (2008), in a study of 596 farms from Kansas, found pesticides to be risk-increasing inputs. This discrepancy in findings may be explained by the effect of inputs varying depending on whether crop growth conditions are good or bad (Horowitz and Lichtenberg 1994) and/or by the use of different types of indicators of pesticide application (Möhring et al. 2020).

ii Since Carpentier (1995) was written in French, readers may refer to Carpentier and Weaver (1997) which describes the estimation of the production functions that were used to calculate the impact of risk aversion on pesticide use reported in Carpentier (1995).

iii The author does not indicate how the cost of risk compares to the expected profit and certainty equivalent.

iv A similar approach (with a coefficient of relative risk aversion set at 2.5 ) was used in Di Falco and Chavas (2009) on data from Ethiopia. The actual risk premium is not reported in the paper but, from Figure 1 on page 609, the risk premium appears to represent less than $10 \%$ of expected income.

${ }^{\vee}$ In these articles, technology parameters and the parameters representing farmers' risk preferences (often a risk aversion coefficient) were estimated within a unique model made of simultaneous equations, in most cases under the assumption that farmers face production risk only. Separate identification of the technology and risk preferences in such models was later called into question by Lence (2009) and Just and Just (2011).

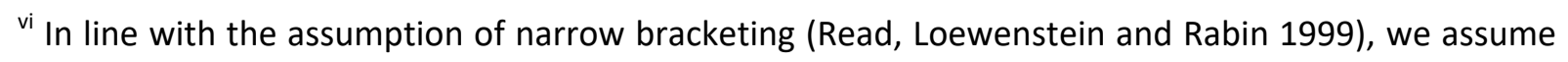
pesticide decisions are made in isolation from other decisions made on the farm. Among the determinants of narrow bracketing are two factors that are relevant for pesticide use: farmers face cognitive resource scarcity and use heuristics (treatment planning) that increase the probability of narrow bracketing in pesticide use. We are aware of only one study pointing to narrow bracketing by 
farmers in their choice of inputs. Using an investment game to experimentally elicit risk preferences, Verschoor, D'Exelle and Perez-Viana (2016) show that risk preferences in the lab significantly explain fertilizer use of Ugandan crop farmers, but not the decision to grow cash crops or the degree of market participation. They suggest that this result can be explained by narrow bracketing in fertilizer use, a decision made in isolation and similar to the decision in the experimental investment game.

vii For calibration of the production function and in order to determine plausible ranges for pesticide use and prices, we relied on observational data from farms producing cereals in northeast France. The major crops produced on these farms were wheat, barley, and rapeseed. We used annual data on winter wheat over the period 1993-2010. For greater details on these data, see e.g., Carpentier and Letort (2011), Femenia and Letort (2016), and Koutchadé, Carpentier and Femenia (2018).

viii Yields can only be positive or null so the generated yield is set at zero when realizations of the random shock produce a negative yield.

${ }^{\text {ix }}$ Empirical estimates of the relative risk aversion coefficient vary on a wide range and estimated coefficients around 6 are not uncommon (e.g.; Chavas and Holt 1996; Saha, Shumway and Talpaz 1994; Sckokai and Moro 2006; cf. Appendix A2).

${ }^{x}$ The empirical analysis has been made using $R$. Programs are available upon request.

${ }^{\mathrm{xi}}$ Historical data for the price of wheat (in EUR) are publicly available here:

https://www.indexmundi.com/commodities/?commodity=wheat\&months=180\&currency=eur

${ }^{\text {xii }}$ Antle (1983) developed a moment-based approach that allows the third and higher moments of the probability distribution of output to be modeled as a function of input. For empirical illustrations of this approach see Di Falco and Chavas $(2006,2009)$.

xiii $\mathrm{A}$ loss aversion coefficient of $\lambda \geq 1$ means that avoiding a loss is valued $\lambda$ times as much as obtaining the same amount as a gain.

${ }^{\text {xiv }}$ There is rare theoretical guidance for the choice of the reference point and the need to make assumptions on where such a reference point is seen as one of the major weaknesses of CPT (Barberis 2013). 
${ }^{x v}$ We also ran one scenario featuring Tversky and Kahneman (1992)'s parameters except for loss aversion being set at 3.50. The optimal input use with the reference point being set at 0 , the median profit, and the maximum profit is 270 EUR, 279 EUR and 279 EUR, respectively. This scenario is not shown in Tables 4 and 5 due to space constraints.

${ }^{x v i}$ A few countries have adopted pesticides taxation, the most commonly cited being Sweden and Denmark. Sweden applies a tax to each kilogram of active substance (€3.64/kg in 2016) while Denmark applies a pesticides tax that is differentiated by the pesticides' category (insecticides; herbicides, fungicides and growth regulators). For greater information on pesticide taxation schemes we refer readers to Böcker and Finger (2016) and Finger et al. (2017).

xvii Femenia and Letort (2016) simulated the impact of an ad valorem tax on pesticides using data from North-eastern France. In their setting farmers were allowed to switch to a low-input technology which implies lower expenditure on fertilizer and pesticides. Their findings showed that a $35 \%$ tax on pesticides would allow the achievement of a $25 \%$ reduction in pesticide use through the combination of two effects: the pesticide tax first increases farmers' probability of adoption of the low-input practice (hence leading to a reduction in pesticide use) and, second, farmers further reduce their pesticide use as a response to the increase in pesticide price. However, most of the reduction in pesticide use is driven by the adoption of the low-input technology. The authors also showed that an increase in crop prices would lower the effectiveness of the taxation policy since higher crop prices lower farmers' incentives to adopt the low-input technology. 